\title{
A Multidimensional Investigation of Sensory Processing in Autism: Parent- and Self-Report Questionnaires, Psychophysical Thresholds, and Event-Related Potentials in the Auditory and Somatosensory Modalities
}

Patrick Dwyer ( $\nabla$ patricksrdwyer@gmail.com )

University of California Davis https://orcid.org/0000-0003-1779-5252

Yukari Takarae

UC San Diego: University of California San Diego

Iman Zadeh

Oracle Corp

\section{Susan M Rivera}

UC Davis: University of California Davis

Clifford D Saron

University of California Davis

\section{Research}

Keywords: autism, sensory, auditory, tactile, event-related potentials, psychophysics

Posted Date: October 12th, 2021

DOl: https://doi.org/10.21203/rs.3.rs-952415/v1

License: (a) (1) This work is licensed under a Creative Commons Attribution 4.0 International License. Read Full License 
A Multidimensional Investigation of Sensory Processing in Autism: Parent- and Self-Report

Questionnaires, Psychophysical Thresholds, and Event-Related Potentials in the Auditory and

Somatosensory Modalities

\author{
Patrick Dwyer* \\ Center for Mind and Brain, UC Davis \\ Department of Psychology, UC Davis \\ MIND Institute, UC Davis \\ patricksrdwyer@gmail.com \\ Yukari Takarae \\ Department of Neurosciences, UC San Diego \\ Department of Psychology, San Diego State University \\ Iman Zadeh \\ Oracle Cloud Infrastructure, Oracle \\ Susan M. Rivera $\dagger$ \\ Center for Mind and Brain, UC Davis \\ Department of Psychology, UC Davis \\ MIND Institute, UC Davis \\ Clifford D. Saron $\dagger$ \\ Center for Mind and Brain, UC Davis \\ MIND Institute, UC Davis \\ *Corresponding author \\ $\dagger$ Co-senior authors
}




\begin{abstract}
Background: Reconciling results obtained using different types of sensory measures is a challenge for autism sensory research. The present study used questionnaire, psychophysical, and neurophysiological measures to characterize autistic sensory processing in different measurement modalities.
\end{abstract}

Methods: Participants were 46 autistic and 21 typically-developing adolescents. Participants and their caregivers completed questionnaires regarding sensory experiences and behaviours. Auditory and somatosensory ERPs were recorded as part of a multisensory ERP task. Auditory, tactile static detection, and tactile spatial resolution psychophysical thresholds were measured.

Results: Sensory questionnaires strongly differentiated between autistic and typically-developing individuals, while little evidence of group differences was observed in psychophysical thresholds. Crucially, the different types of measures (neurophysiological, psychophysical, questionnaire) appeared to be largely independent of one another. However, we unexpectedly found autistic participants with larger auditory Tb ERP amplitudes had reduced hearing acuity, even though all participants had hearing acuity in the non-clinical range.

Limitations: The autistic and typically-developing groups were not well-matched, although this limitation does not affect our main analyses regarding convergence of measures within ASD. The autistic sample in the present study is not representative of the whole autistic constellation, limiting generalizability. Auditory ERPs and auditory thresholds were measured with nonequivalent stimuli.

Conclusions: Overall, based on these results, measures in different sensory modalities appear to capture distinct aspects of sensory processing in autism, with relatively limited convergence between questionnaires and laboratory-based tasks. Generally, this might reflect the reality that laboratory tasks are often carried out in controlled environments without background stimuli to 
compete for attention, a context which may not closely resemble the busier and more complex environments in which autistic people's atypical sensory experiences commonly occur. For this reason, sensory questionnaires may be more practically useful assessments of autistic people's real-world sensory challenges. Further research is needed to replicate and investigate the drivers of the unexpected association we observed between auditory Tb ERP amplitudes and hearing acuity, which could represent an important confound for ERP researchers to consider in their studies.

Keywords: autism, sensory, auditory, tactile, event-related potentials, psychophysics 
Increasing evidence highlights the importance of atypical sensory processing within the autistic phenotype. Not only do a number of studies suggest that atypical sensory processing can emerge early in development and predict later social features of Autism Spectrum Development (ASD, e.g., (1-4)), but sensory processing has practical importance as a correlate (5) or aspect (6) of autistic people's quality of life. ${ }^{1}$ Atypical sensory processing has also been linked to autistic people's participation in activities $(7,8)$, anxiety levels $(9,10)$, and sleep problems $(11,12)$. A recent study even suggests that some sensory differences in ASD are related to telomere lengths, although the study was not able to confirm the causal direction of the associations (13).

However, the investigation of sensory processing and sensory experiences in ASD can be exceedingly complex, with different measures such as questionnaires, psychophysical thresholds,

${ }^{1}$ There is an ongoing debate in the autism world regarding whether person-first (i.e., "person with autism”) or identity-first (i.e., "autistic person”) language should be used to describe autism. In this paper, we have chosen to use identity-first language. Although not all individuals on the autism spectrum prefer identity-first language (Bury et al., 2020), many do (Bury et al., 2020; Kenny et al., 2016). Furthermore, some arguments suggest that person-first language may reflect and/or accentuate stigma towards autism (Gernsbacher, 2017; Sinclair, 2013). We have also chosen to use the term "Autism Spectrum Development" as an alternative to "Autism Spectrum Disorder" or "Autism Spectrum Condition," terms which are not widely endorsed by autistic individuals (Kenny et al., 2016). The phrase "development" is also a neutral descriptor, whereas the term "disorder," and perhaps the term "condition" as well, appear to suggest subjective value judgements that are arguably unnecessary and unhelpful in scientific research. 
and neurophysiological responses frequently appearing to yield radically different patterns of ASD-TD group differences.

\section{Questionnaire Reports}

A number of prior studies have used parent- (e.g., (14-17)) or self-report (e.g., (18-20)) questionnaires to examine different patterns of atypical sensory processing, such as hyposensitivity, hypersensitivity, and sensory interests, in ASD. Results obtained using both parent- and self-report questionnaires indicate that autistic individuals generally process and respond to sensory stimuli quite differently from typically-developing (TD) individuals (15-20). Furthermore, both parent- (reviewed by (21)) and self-report (22) studies have found considerable heterogeneity in autistic people's sensory experiences: subgroups of individuals might be reported to have particularly high or low levels of sensory behaviours or experiences from some subscales of a given measure. However, scores on different sensory patterns such as hypersensitivity and hyposensitivity are positively correlated in ASD (23-25). Thus, even though some autistic individuals appear to display particularly high or low levels of only some patterns of sensory behaviour or experience, there is an overall tendency for autistic people with high levels of any given pattern to also have high levels of other sensory patterns.

\section{Behavioural Thresholds}

Other research has examined sensory processing in autism using very different methods, such as behavioural measurement of sensory thresholds. However, psychophysical studies appear markedly less likely than questionnaire studies to find differences between ASD and TD groups, and such differences as are observed may be much more specific to particular modalities and tasks, or to subgroups.

In the tactile domain, some prior research using static stimuli (such as Von Frey monofilaments) suggests that autistic and typically-developing individuals do not differ in their 
touch detection thresholds $(26,27)$, and while other findings suggest poorer tactile static detection thresholds in ASD (28), this might reflect conservatism in perceptual decision-making and reporting (29). Some studies do suggest detection thresholds for vibrotactile stimuli could be enhanced in ASD $(26,30,31)$. This effect may, however, depend on frequency and body site $(26,30)$ and is not universally reported $(28,32)$. Interestingly, some autistic adults may have diminished density of small intraepidermal nerve fibers, which was related to elevated sensory thresholds to thermal stimuli (33).

In the auditory domain, autistic and typically-developing groups might not differ in hearing acuity (34-36) or exhibit only modest differences that reverse directionality across frequencies (37). However, enhanced pitch discrimination has been reported in subgroups within $\operatorname{ASD}(38,39$, see also (40)). There appear to be other examples of heterogeneity in this literature besides enhanced frequency discrimination subgroups; notably, autistic individuals appear more likely to exhibit deafness/hardness of hearing and blindness/visual impairment $(41,42)$, despite the aforementioned studies reporting minimal or no overall ASD-TD differences in hearing and visual acuity. Thus, overall, sensory thresholds in ASD appear to vary across individuals and perhaps across types of stimuli. However, normal detection of stimuli in ASD can coexist with markedly abnormal tolerance of stimuli (e.g., (35)), such that sensory thresholds alone cannot account for the diversity of sensory experiences in autism.

\section{Neurophysiological Event-Related Responses}

Electrophysiological event-related potentials (ERPs) and magnetoencephalographic event-related fields (ERFs) have also been widely used to investigate auditory processing in ASD (43-45). However, such studies need to be interpreted with caution as cortical ERPs are known to change in morphology with age in TD. Auditory ERPs over fronto-central scalp undergo a major shift around 9-14 years of age, when the child frontocentral P1-N2 complex 
evolves into the central P1-N1-P2-N2 complex seen in adults (see (46-49)). Auditory temporal $\mathrm{Tb}$ or $\mathrm{N} 1 \mathrm{c}$ responses appear relatively stable over this age range $(46,48)$; the $\mathrm{Tb}$ is a large negative-going response which appears over temporal sites around $\sim 150 \mathrm{~ms}$ after the onset of an auditory stimulus. Another response that appears to be stable through the childhood to adolescence transition is an early somatosensory ERP, a contralateral centro-parietal positivity occurring around $\sim 55 \mathrm{~ms}(50)$. This contralateral positivity might correspond to the canonical adult P60 component (see, e.g., (51-53)).

A recent review suggests latencies of the auditory P1 response are prolonged in ASD, while $\mathrm{Tb}$ and $\mathrm{N} 2$ amplitudes are attenuated (45). Although the review did not formally metaanalyze group differences in $\mathrm{Tb}$ latencies, it also notes that prior studies examining $\mathrm{Tb}$ latencies

reported substantial delays in the ASD group (45). Interestingly, prior research also suggests that there is considerable heterogeneity in auditory responses within both ASD and TD individuals (54-56). Furthermore, although the neurophysiological literature regarding somatosensory responses in ASD is not as well-developed as that investigating auditory responses, a few prior studies have documented that ERPs and ERFs to somatosensory stimuli in ASD might be delayed $(57)$ or reduced in amplitude $(58,59)$ relative to TD. While the latency differences observed by (57) involved a later ERF, the M200, the amplitude differences observed in $(58,59)$ occurred in time windows overlapping with the P60 response.

However, it is important to consider how ERPs relate to other sensory measures and to the subjective sensory experiences of autistic individuals.

\section{Integrating Methods}

In a recent review of the field, Uljarević and colleagues (60) identify discrepancies between different types of sensory measures as a major challenge for researchers investigating sensory processing and its heterogeneity in ASD. These authors suggest that sensory features 
should be assessed using multiple approaches, such as mixtures of questionnaire, physiological, and observational measures, as each type of measure might provide unique information. Multidimensional investigations of this type would also allow for exploration of whether and how different types of sensory measures are associated with one another and to subjective experiences (61).

\section{Questionnaires and Behavioural Thresholds.}

Theories informing the design of widely-used sensory questionnaires, such as the Sensory Profile (SP) and Adolescent/Adult Sensory Profile (AASP), suggest that some form of stimulus detection or behavioural reaction threshold is captured by these measures (62). However, prior research comparing behavioural acuity measures to questionnaire measures in ASD has yielded mixed results. Studies have suggested a lack of robust, consistent associations between tactile thresholds and questionnaire reports of sensory experiences and behaviours across multiple modalities $(29,32)$. That being said, elevated hearing thresholds and poorer intensity discrimination might be related to questionnaire reports of greater sensitivity and avoidance (36,39). Tactile temporal resolution might show similar patterns (32).

At a theoretical level, there are large differences between the sensory processing occurring in an individual's natural environment and that required in the laboratory during psychophysical detection and discrimination tasks. In natural environments, individuals are often exposed to many stimuli simultaneously. Attention capture by aversive stimuli in these busy natural environments might be a path towards subjective hypersensitivity and experiences of sensory distress and overload; indeed, prior research suggests there may be an elevated propensity towards attentional capture in autism (e.g., (63-65)). Participants (or parent proxy reporters) completing sensory questionnaires would presumably then report on these experiences of attention capture and sensory distress. In contrast, psychophysical tasks provide participants 
with clear attention instructions in controlled, low-stimulation environments. In the absence of distractors capable of capturing or overwhelming attention, it is possible that autistic and nonautistic individuals might process stimuli very similarly. These differences between natural environments and laboratory environments might, in the absence of clinical impairments in sensory acuity, be expected to seriously limit the convergence of these two types of measures. Questionnaires - especially self-report questionnaires (see (66)) - might thus more directly capture the real-world subjective sensory experiences of autistic individuals.

\section{Neurophysiological Responses and Questionnaires.}

Some prior studies have examined, in ASD, the convergence between questionnaire reports of sensory processing and ERP/ERF responses to auditory stimuli. For example, larger early neural responses to sounds could be related to reports of auditory distractibility or sensory sensitivity $(55,67)$, and weaker later auditory responses might trend towards being associated with reports of hyporesponsiveness (68). Prior research has also explored associations between reported sensory behaviours and auditory mismatch/P3 responses $(69,70)$ as well as ERP indices of auditory habituation (71). Weaker neural responses to air puffs, relative to sham, appear to correlate with reports of tactile hypo-responsiveness, and at a trend level, larger neural responses may be related to reported tactile hyper-responsiveness (72).

It appears intuitively reasonable to imagine that subjective experiences of hyper- or hyporesponsivity to stimuli (as reported in questionnaires) should be related to neural hyper- and hypo-responsiveness, especially when brain responses are recorded in a context comparable to the complex, uncontrolled contexts in which atypical sensory experiences occur in real life. In this sense, it is not surprising to observe associations between ERPs and sensory questionnaire scores when ERPs are recorded in passive paradigms while background stimuli compete for attention (as in $(55,68)$ ). However, convergence between sensory questionnaire scores and 
amplitudes of ERPs has also been found when recorded while participants complete active tasks, requiring maintenance of particular attentional sets, in controlled, low-stimulation environments (e.g., (67)).

\section{Neurophysiological Responses and Behavioural Thresholds.}

Unfortunately, there is currently minimal research regarding associations between neurophysiological responses and behavioural/psychophysical sensory measures in ASD. Admittedly, one study has reported that there are no associations between latency of somatosensory ERFs and tactile spatial resolution or tactile proprioception (57). It is therefore tempting to speculate that - at least in autistic individuals with normal-range sensory thresholds - there would be little direct relationship between the magnitude of a neurophysiological response to a clear, suprathreshold stimulus and the ability to detect a much subtler, nearthreshold stimulus, but further research is clearly needed to explore this question not only in the somatosensory modality but also other modalities.

\section{Present Study}

The present study examines sensory processing in ASD using a mixture of physiological, behavioural/psychophysical, and questionnaire measures in well-characterized groups of autistic and typically-developing children. More specifically, this study examines auditory ERPs, somatosensory ERPs, hearing thresholds, tactile static detection thresholds, tactile spatial resolution thresholds, parent-report sensory questionnaires, and self-report sensory questionnaires from 11-14-year-old participants. This rich, multimethod dataset not only allows the present study to examine ASD-TD group differences, but to compare the results obtained with different methods and to determine whether they show convergence or represent separate and distinct aspects of sensory processing.

Hypotheses: 
1. Autistic individuals will, in comparison to typically-developing participants, be reported on questionnaires to exhibit more atypical sensory processing in all domains (e.g., more hyper- and hypo-sensitivity, more sensory interests, more enhanced perception), in keeping with prior research;

2. Autistic and typically-developing individuals will not differ from one another in hearing acuity, tactile detection thresholds, or tactile spatial resolution thresholds;

3. Amplitudes of the auditory Tb and somatosensory P60 ERPs will be attenuated in the ASD group, and their latencies will be delayed; and

4. Auditory Tb and somatosensory P60 amplitudes in the ASD group will not be associated with hearing and tactile psychophysical thresholds.

\section{Methods}

\section{Participants}

Participants were recruited through a mixture of community advertising and extant research contact databases, including the UC Davis Health MIND Institute Research Volunteer Registry. 46 autistic (41 male, 5 female) and 21 typically-developing participants (14 male, 7 female) provided usable data on at least one questionnaire, psychophysical, or ERP measure and were included in the present study (Table 1). 26 participants (13 autistic, 13 typicallydeveloping) provided usable data on all measures (including all questionnaire subscales).

\section{INSERT TABLE 1 ABOUT HERE}

All included participants were required to have Wechsler Intelligence Scale for ChildrenIV (73) Perceptual Reasoning Index (PRI) scores of at least 65. The PRI index was chosen as a basis for this inclusion criterion as its subtests impose few percepto-motor demands, and this could make the PRI index a more suitable measure of fluid cognitive ability in ASD than other WISC-IV indices $(74,75)$. Exclusionary criteria for both the ASD and TD groups included a 
history of non-febrile seizures, a history of serious head trauma, use of antipsychotic or barbiturate medications, known hearing loss, and known visual impairment.

The autism spectrum diagnoses of 43 autistic participants were verified by clinical judgement and using the Autism Diagnostic Observation Schedule (ADOS; (76)); all of these participants met "autism" or "autism spectrum" criteria per the revised algorithms published by Gotham et al. (77) and Hus and Lord (78). One further autistic participant did fell a point short of ADOS criteria, but this participant did meet autism criteria per the ADI-R diagnostic algorithm and clinical judgement suggested that they met DSM-IV diagnostic criteria for a pervasive developmental disorder. The remaining two autistic participants' diagnoses were supported by a recent $(<1.25$ years) external diagnostic evaluation that included administration of the ADOS.

The parent-report Social Communication Questionnaire (SCQ; (79)) and Autism Spectrum Screening Questionnaire (ASSQ; (80)) were used to screen typically-developing participants for autism. Exclusion criteria for the TD group included parent reports of a history of developmental, learning, or genetic conditions or neurodivergence; as well as first-degree genetic relatives with known autism spectrum diagnoses.

\section{Sensory Questionnaire Measures}

\section{Adolescent/Adult Sensory Profile (AASP).}

The Adolescent/Adult Sensory Profile (AASP) is a self-report questionnaire with 60 items measuring the frequency of sensory behaviours and experiences using a 5-point Likert scale (81). It is based on the model of sensory processing proposed by Dunn (62), which describes sensory processing in terms of (1) neurological thresholds, understood in terms of variation in the amount/intensity of a stimulus needed for detection and registration to occur, and (2) either behaving in accordance with a threshold or "counteracting" thresholds by seeking or 
avoiding stimuli. As a result, the AASP provides four "quadrant" scores reflecting the interaction of thresholds and behavioural responding:

- Low registration: High thresholds (i.e., poor detection of stimuli) and passive responding (i.e., despite low stimulation, not attempting to seek stimuli).

- Sensory seeking: High thresholds and counteracting of high thresholds through stimulation-seeking.

- Sensory sensitivity: Low thresholds (i.e., enhanced detection of stimuli) and behavioural responding in accordance thresholds (e.g., becoming distracted by incoming stimuli).

- Sensory avoiding: Low thresholds and counteracting of these thresholds through avoiding stimulation.

The AASP, which was developed for use with individuals aged 11 years or older, examines these quadrants through items relating to the taste/smell, movement, visual, touch, activity, and auditory modalities. In the present study, usable AASP data were obtained from 34 autistic and 18 typically-developing participants. 12 missing item responses $(0.38 \%)$ were imputed using DataWig, a machine learning Python package (82).

\section{Sensory Experiences Questionnaire-3.0 (SEQ-3.0).}

The Sensory Experiences Questionnaire Version 3.0 (SEQ-3.0) is a caregiver-report questionnaire with 97 items measuring the frequency of sensory behaviours using a 5-point Likert scale (14). The items load onto the four sensory response pattern factors of hyporesponsiveness (HYPO), hyper-responsiveness (HYPER), sensory interests, repetitions, and seeking (SIRS), and enhanced perception (EP). SEQ-3.0 items examine the auditory, visual, tactile, gustatory/olfactory, and vestibular/proprioceptive modalities as well as social and nonsocial contexts. Although the SEQ-3.0 was developed for children in the age range of $2-12$ years, it has the advantage of having been specifically designed with a focus on autism $(14,15)$. 
In the present study, usable SEQ data were obtained regarding 44 autistic and 21 typicallydeveloping participants. 27 missing item responses $(0.43 \%)$ were imputed using DataWig (82).

Sensory Profile (SP).

The Sensory Profile (SP) is a caregiver-report questionnaire with 125 items measuring the frequency of sensory behaviours (83), originally developed for use with children aged $3-10$. Like the AASP, it is based on the quadrant model developed by Dunn (62); however, the SP has a total of nine factors rather than the four quadrants in the AASP. Dunn (62) suggests that the SP factor "sensation seeking" corresponds with sensation seeking quadrant; that the SP factor "emotionally reactive" relates to the sensation avoiding quadrant; that the SP factors "low endurance/tone," "poor registration," and "sedentary" reflect similar processes to the poor registration quadrant; and that the SP factors "oral sensory sensitivity," "inattention/distractibility," and "sensory sensitivity" reflect similar processes to the sensory sensitivity quadrant. The SP's "fine motor/perceptual" scale is not believed to correspond to a specific quadrant in AASP (62). The SP also differs from the AASP in its inclusion of additional sensory modalities (body position and emotional/social).

In the present study, SP data from all modalities were obtained regarding 34 autistic and 19 typically-developing participants; another 4 autistic and 1 typically-developing participants had responses from some modalities but not others. 12 missing item responses $(0.18 \%)$ were imputed using DataWig (82).

Data from all modalities on all three questionnaires (AASP, SP, and SEQ) were obtained regarding 30 autistic and 17 typically-developing participants.

\section{Sensory Behavioural/Psychophysical Measures}

Audiometry. 
An Otovation Amplitude T4 clinical audiometer and headphone system was used to measure monaural pure tone auditory detection thresholds while participants were seated in a dimly-lit, shielded, audiometrically quiet chamber. Participants were instructed to press a button whenever they heard a tone, even if it was really soft or if they just thought they might have heard a tone. Stimuli were $1000 \mathrm{~ms}$ pure tones of $125,250,500,1000,2000,4000$, and 8000 $\mathrm{Hz}$, presented at a random interstimulus interval of $1200-2500 \mathrm{~ms}$. Starting intensity level was set at $40 \mathrm{~dB}$ HL and levels were either increased in steps of $5 \mathrm{~dB}$ or decreased in steps of $10 \mathrm{~dB}$ using an automated implementation of the Hughson-Westlake method. The minimum possible intensity was $-10 \mathrm{~dB}$ HL. One participant with monaural clinical hearing loss (PTA $\geq 20 \mathrm{~dB}$ ) was excluded, after which usable audiometric data remained from a total of 40 autistic and 19 typically-developing participants.

\section{Tactile Static Detection.}

Static Von Frey monofilaments (84), also referred to as Semmes-Weinstein monofilaments, were used to estimate tactile static detection thresholds. Participants were seated at a table in front of a large, opaque cardboard folding screen. Participants inserted their right hands through a gap in the folding screen, which was obstructed by a curtain. To prevent movement, participants' index fingers were secured to the table with double-sided tape. Filaments of between 0.41 and $0.06 \mathrm{~mm}$ - corresponding approximately to between 8.51 and 0.005 grams of force - were then applied to the participant's index finger in four blocks (two ascending, two descending), with a dummy trial included in each block. Participants were asked to report whether or not they could feel the stimulus. In descending blocks, presentation was halted after two consecutive misses; in ascending blocks, presentation was halted after two consecutive hits. In the second block of each order, presentation began with filaments of the diameter from three trials before their previous threshold. If participants reported that they could 
feel the stimulus in a dummy trial, the block was repeated. Thresholds were calculated and reported using a $\log _{10}$ scale of approximate actual forces, corresponding to a linear scale of perceived forces, that was provided by the manufacturer (84). Approximate log forces from the final trials in each of the four blocks were averaged together to produce an estimate of the participant's tactile detection threshold. Thresholds are reported here only from right-handed participants (i.e., those with positive laterality quotients on a modified Edinburgh Inventory; see (85)) because tactile thresholds could differ between dominant and non-dominant hands (86). Measures from 31 autistic and 20 typically-developing right-handed participants were available.

\section{Tactile Spatial Resolution.}

JVP domes (87) were used to estimate tactile spatial resolution. JVP domes are hemispherical plastic domes, the heads of which contain gratings with equidistant bars and grooves. Different domes have different bar and groove widths which vary between 3.00 and $0.35 \mathrm{~mm}$. Participants were seated in front of the opaque screen described above, in a procedure adapted from Bleyenheuft and colleagues (88); JVP domes were applied to the index finger, with participants being instructed to report whether the orientation was "sideways" or "longways." Participants completed five practice trials with the largest grating before the same grating was applied in random orientations for ten trials. The test then continued with ten further trials using the next-largest grating, and so on, until the probability of correct answers reached $50 \%$ at any grating level. $75 \%$ tactile spatial acuity thresholds were estimated using linear interpolation $(88,89)$ :

$$
\text { Threshold }=g_{\text {below }}+\frac{0.75-p_{\text {below }}}{p_{\text {above }}-p_{\text {below }}}\left(g_{\text {above }}-g_{\text {below }}\right)
$$

Here, $g$ is grating width and $p$ is the probability of reporting the correct orientation at a given grating width. The grating width "above" means the lowest width yielding $p$ greater than 
$75 \%$, while the grating width "below" means the following grating width (where $p$ has dropped below $75 \%$ ). Where $p$ remained below or above $75 \%$ at all grating widths tested, thresholds were recorded as $3.00 \mathrm{~mm}$ or $0.35 \mathrm{~mm}$, respectively. Thresholds were obtained from 41 autistic and 19 typically-developing right-handed participants.

\section{Questionnaire and Psychophysical Analyses}

ASD - TD Group Comparisons.

Comparisons of questionnaire scores and tactile thresholds between the ASD and TD groups used Wilcoxon-Mann-Whitney tests. Furthermore, when any ordinal tests reached statistical significance, linear parametric ANCOVA was used to explore whether covarying for WISC PRI scores would attenuate effects. Analyses of the questionnaire data were corrected using the Holm-Bonferroni procedure.

For comparisons of hearing thresholds, we employed a two-tailed maximum-based permutation test (using a custom R script adapted from (90)). Cliff's $\delta$ (91), an ordinal effect size measure, was used to compare hearing thresholds between the ASD and TD groups at each frequency for each ear, separately. The maximum value of $\delta$ - the largest group difference in hearing thresholds - was then compared to a permutation distribution of 10,001 $\delta$ values. In addition, for ease of interpretation, we used Wilcoxon-Mann-Whitney tests to compare groups on pure tone averages (PTAs), thresholds averaged across frequencies.

\section{Psychophysical - Questionnaire Associations.}

Pearson's correlation coefficient $(r)$ was used to index associations between questionnaire scores and psychophysical auditory and tactile thresholds within the ASD group. Hearing thresholds were averaged across frequencies and ears.

We focused analyses on questionnaire subscales and items that one might expect to be the most relevant to psychophysical thresholds in the auditory and tactile modalities. From the SEQ- 
3.0, the Enhanced Perception (EP) pattern seemed most relevant. Ausderau et al. (14) suggest that EP reflects "superior acuity in the awareness of specific sensory stimuli" and might be related to low thresholds. As the EP pattern includes four items from the auditory modality, we summed these items to produce an auditory EP score. However, the SEQ has only a single EP item from the tactile modality (regarding skill identifying unseen objects in bags), so we decided to use the overall SEQ EP subscale to examine associations with tactile thresholds.

As the quadrant model of Dunn (62) suggests that both sensory sensitivity and sensory avoiding reflect lower thresholds, and given that there were 3-4 items for each of these patterns from both the tactile and auditory modalities of the AASP, we summed these to produce AASP "Low Threshold" scores for each modality. The caregiver-report SP distinguishes between "high" and "low" threshold items, so low threshold auditory (items 1-5) and tactile items (items 29-39) were summed to produce SP "Low Threshold" scores for each modality.

\section{Neurophysiological Measure}

\section{EEG Procedure and Stimuli.}

Electrophysiological data in this study were collected as part of a trimodal multisensory integration task, in which auditory, somatosensory, visual, audio-somatosensory, audiovisual, visuo-somatosensory, and audiovisual-somatosensory stimuli were intermixed at a random interstimulus interval of $1000-2250 \mathrm{~ms}$. A total of 920 stimuli ( 130 per condition) were presented in ten blocks. Only data from the auditory-alone and somatosensory-alone conditions are included in this report.

Stimuli were delivered while participants were seated in a dimly-lit, electrically shielded, quiet testing chamber in front of a custom-built desktop stimulus delivery and RT-recording apparatus (Figure 1). Auditory stimuli were $20 \mathrm{~ms}, 63 \mathrm{~dB}$ SPL (at participants ears) noise bursts shaped to the average spectrum of human speech (92) in order to increase activation of lateral 
belt areas of the spatial auditory system $(93,94)$. Sounds were delivered monophasically from two 3" loudspeakers (JBL gto326) located to either side of the central visual stimulus location and the resultant sound appeared to come from the same location as the locations of the visual and somatosensory stimuli.

\section{INSERT FIGURE 1 ABOUT HERE}

Somatosensory stimuli were $8 \mathrm{~ms}$ mechanical taps (single cycles of a $120 \mathrm{~Hz}$ cosine wave) delivered to participants' right index fingers as they placed their hand on an immovable mouse at the center of the desktop (Figure 1). Stimuli were delivered by actuating the left mouse button using a linear motor mounted below the mouse. To deliver what would be perceived as a single tap with no overshoot or rebound, the linear motor (a modified 3" Fosgate Punch car radio speaker) was driven by a low distortion audio signal using a Benchmark DAC1 digital-to-analog converter and Hafler Transnova amplifier whose extended low-frequency response and high damping factor eliminated perceptible overshoot and rebound. To ensure repeatable levels of tactile stimulation, finger pressure on the left mouse button was continuously measured using a Grass FT03 Force-Displacement Transducer located in line with the linear motor output (see Supplementary Figure 1). The output of the force transducer via a Grass P22 amplifier was fed into a Coulbourn V21-10 window discriminator, which was adjusted for each participant to define a pressure window representing light finger pressure on the mouse button. Too light, inrange, and excessive pressure were indicated via a light box visible to the experimenter with the participant and trials only proceeded with in-range pressure. Intensity of the tactile tap was adjusted to be subjectively roughly equivalent to the modest noise bursts and visual stimuli. The force transducer also served to generate a button-press motion signal used to determine RT. 
Although careful alignment, acoustic shielding and robust construction of somatosensory stimulator materials mitigated acoustic output from the somatosensory stimuli, a quiet thump could nonetheless be heard accompanying the stimuli. This sound was effectively masked by continuously playing a low-frequency noise signal (peak power between 100 and $200 \mathrm{~Hz}$ ) in the background during the experiment.

Visual stimuli (not reported here) were generated by $20 \mathrm{~ms}$ illumination of a strip of LEDs diffused using a translucent circular opening in the center of the desktop (see Figure 1). These flash stimuli were $85 \mathrm{~cd} / \mathrm{m}^{2}$ with a $3: 2$ contrast ratio.

Participants were instructed to fixate a small red LED at the center of the circular opening and respond to all stimulus events (whether alone or in simultaneous combination) by pressing the left mouse button with their right index finger as quickly as possible. This button was also used to mechanically deliver the somatosensory stimuli to the right index finger. Fixation compliance was monitored using a low-light camera focused on the participants eyes. The experimenter in the recording chamber halted the delivery of stimuli when fixation was lost. Thus, EEG data were recorded as part of an active behavioural task, in a controlled environment, and only while participants appeared (overtly, via fixation, at least) to be attending to stimuli. This tightly controlled data acquisition context, with an active task requiring sustained attention, should certainly be borne in mind when considering convergence with other sensory measures.

Admittedly, the intermixed nature of the stimuli makes this a multisensory context, imposing a need to frequently switch attention between modalities, and there may be ASD-TD differences in multisensory attention switching (95). However, the lab environment is still a strictly controlled one; there are no distracting background stimuli, and stimuli in all modalities emanate from the same multisensory desktop. Furthermore, it should be noted that the 
intermixed presentation of these stimuli might reduce habituation/repetition suppression and make habituation less of a contributor to any ASD-TD group differences.

\section{EEG Acquisition and Processing.}

Continuous EEG was recorded from $125 \mathrm{Ag} / \mathrm{AgCl}$ scalp electrodes in an equidistant montage (www.easycap.de) and digitized at $1000 \mathrm{~Hz}$ (Compumedics Neuroscan Synamp2) with $\mathrm{Cz}$ as a reference. Three-dimensional electrode locations for each individual participant relative to bony fiducials were obtained using a Polhemus Patriot magnetic field-based 3D digitizer. Eye movements were monitored using horizontal and vertical EOG. Data were then imported into BESA Research 5.3, low-cut filtered (0.4 Hz, forward causal, $6 \mathrm{~dB} / \mathrm{oct}$ roll-off), epoched ($200 \mathrm{~ms}$ to $+1100 \mathrm{~ms}$ ), and average-referenced. Trials with extreme amplitudes, trials with EOG events between $-200 \mathrm{~ms}$ and $+400 \mathrm{~ms}$, and trials lacking behavioural responses were removed and bad channels were indicated. The remaining data were then entered into a second-order blind source identification (SOBI) independent components analysis using custom MATLAB code with advanced visualization capabilities provided by the Semi-Automatic Artifact Removal Tool (SMART; (96)). Putatively neural components were then reconstructed with epochs spanning -200 to $+800 \mathrm{~ms}$. Averages were generated for the unisensory auditory and somatosensory conditions. The averaged data were exported to CARTOOL (97) and inspected for electrolyte bridging and any further bad channels (heavily contaminated channels may be reconstructed with very low amplitude after removal of artifactual signal source). Bad channels were interpolated via 3-dimensional spline (98). ERPLAB (99) was used to apply high-cut filters (50 Hz Butterworth, zero-phase, $24 \mathrm{~dB} / \mathrm{oct}$ ) and to apply a baseline correction (100 ms prestimulus).

Usable ERP data were obtained from 33 autistic and 18 typically-developing participants. Counts of usable ERP trials, and of trials eliminated during data processing, are presented by 
diagnostic group and modality condition in Table 2. Overall, autistic participants had significantly fewer usable somatosensory trials and trended towards having fewer auditory trials than typically-developing participants.

\section{INSERT TABLE 2 ABOUT HERE}

\section{ERP Analysis.}

We chose to focus ERP analyses on the canonical auditory Tb and somatosensory P60 components, due to their developmental stability in the age range of the present study (see $(46,48,50))$ and their prominence over the scalp.

The auditory $\mathrm{Tb}$ response was examined by averaging across a set of left and right hemisphere temporal channels selected by visual inspection to align with the observed scalp topography of the grand average $\mathrm{Tb}$ (see Figure $6 \mathrm{~A}$ below) collapsed across groups. $\mathrm{The} \mathrm{Tb}$ time window was defined as $\pm 30 \mathrm{~ms}$ on either side of the grand-averaged $\mathrm{Tb}$ peak across both hemispheres and groups (165 ms), or 135 - $195 \mathrm{~ms}$ (Figure 5A). Tb amplitudes over each hemisphere were the mean amplitudes across electrodes over this window. Tb latencies were $50 \%$ fractional area latencies within this window (i.e., the time points that divided the waveform area into two equal halves; see Luck, pp. 296-299 (100)).

The somatosensory P60 response was examined over contralateral (left hemisphere) centro-parietal channels that, by visual inspection, appeared to correspond to the observed scalp topography of the P60 (see Figure 6B). Due to the narrowness and sharpness of this early component, the P60 time window was defined as $\pm 20 \mathrm{~ms}$ on either side of the grand-averaged P60 peak across both groups (58 ms), or 38 - $78 \mathrm{~ms}$ (Figure 5B). P60 amplitudes were quantified as mean amplitudes and P60 latencies as 50\% fractional area latencies. 
ANOVA was used to compare ERP amplitudes and latencies across groups and, in the case of the Tb response, across hemispheres. Significant group differences were subsequently probed with ANCOVA, covarying for WISC PRI scores and sensory thresholds.

\section{ERP - Psychophysical/Questionnaire Associations.}

Pearson's correlation coefficient ( $r$ ) was used to index associations, within the ASD group, between ERP amplitudes and psychophysical thresholds as well as questionnaire scores. For these analyses, auditory $\mathrm{Tb}$ amplitudes were averaged across hemispheres and pure tone average hearing thresholds were collapsed across ears.

To limit the number of correlations, we chose to examine only associations between auditory $\mathrm{Tb}$ amplitudes and the respective sums of all auditory items from each of the three questionnaires, not specific factors/patterns. Similarly, we only examined associations between P60 amplitudes and the respective sums of all tactile items from each of the three questionnaires. For clarity, we considered only SP items 1-8 to be auditory and only items $29-46$ to be tactile. ERP-psychophysical correlations were corrected for three multiple comparisons, and ERP-questionnaire correlations for six, using the Holm-Bonferroni procedure. 


\section{Results}

\section{Psychophysical and Questionnaire Group Comparisons}

SP.

Autistic participants had significantly higher levels of each of the sensory patterns represented by all subscales (Table 3 , Figure $2 A$ ).

\section{INSERT TABLE 3 ABOUT HERE}

\section{AASP.}

Autistic participants had significantly higher levels of the sensory patterns indexed by AASP Low Registration, Sensory Sensitivity, and Sensation Avoiding scores than typicallydeveloping participants (Table 3, Figure $2 B$ ). However, the autistic and typically-developing groups did not differ in levels of AASP Sensation Seeking, $p=.98, \delta=.00$.

\section{INSERT FIGURE 2 ABOUT HERE}

\section{SEQ-3.0.}

Autistic participants had significantly and robustly higher SIRS, HYPO, EP, and HYPER scores than typically-developing participants (Table 3, Figure 2C); these high scores reflect higher levels of each of these sensory patterns.

\section{Hearing Acuity.}

Permutation testing across both ears and all frequencies found a modest trend towards between-group differences in hearing acuity, $p=.09$ (Figure 3A). Groups did not significantly differ in pure tone average (PTA) from right ear, Wilcoxon-Mann-Whitney $p=.94, \delta=-.01$ (Figure $3 C$ ), or collapsing across both ears, $p=.25, \delta=-.19$. However, there was a small and nonsignificant trend for the autistic group to have lower PTA thresholds - better hearing acuity in the left ear, $p=.11, \delta=-.26$ (Figure $3 B)$.

\section{INSERT FIGURE 3 ABOUT HERE}

\section{Tactile Static Detection.}


There was no significant group difference in Von Frey hair detection thresholds, Wilcoxon-Mann-Whitney $p=.50, \delta=.11$ (Figure $4 A)$.

\section{Tactile Spatial Resolution.}

There was no significant group difference in tactile spatial acuity, Wilcoxon-MannWhitney $p=.21, \delta=.21$. Interestingly, visual inspection of the data (Figure $2 B$ ) suggests a bimodal distribution of participants, with one group of participants having higher thresholds. While this might in part reflect a floor/ceiling effect, prior research suggests thresholds around 1 $-2 \mathrm{~mm}$, within the range of our equipment, are typical in this age range $(88,101,102)$.

\section{INSERT FIGURE5 ABOUT HERE}

\section{Psychophysical - Questionnaire Associations}

After correcting for multiple comparisons, we found no significant correlations between hearing thresholds and AASP/SP auditory low threshold scores or SEQ auditory EP scores; between Von Frey thresholds and AASP/SP Tactile Low Threshold or SEQ overall EP scores; or between JVP dome thresholds and AASP/SP Tactile Low Threshold or SEQ overall EP scores, all Holm-Bonferroni corrected $p ' s \geq .33$.

\section{ERP Group Comparisons}

\section{Auditory Tb.}

In a mixed ANOVA, the amplitude of the auditory $\mathrm{Tb}$ response was larger in typicallydeveloping than autistic participants, $F(1,49)=4.24, p=.04, \eta_{G}^{2}=.06$ (Figures 5A, 5C, 6A). Using ANCOVA to covary for WISC PRI scores slightly attenuated the main effect of diagnostic group such that it was no longer significant, $F(1,48)=3.14, p=.08$, and further covarying for hearing thresholds (in those participants with hearing threshold data) attenuated it more, $F(1,45)$ $=1.63, p=.21$. Amplitudes were also larger over the left hemisphere than the right, $F(1,49)=$ 
$5.89, p=.02, \eta_{G}^{2}=.02$. There was no interaction of group and hemisphere, $F(1,49)=0.66, p=$ $.42, \eta_{G}^{2}=.00$.

\section{INSERT FIGURE 5 ABOUT HERE}

Tb latencies were slightly faster in TD participants than ASD participants, $F(1,49)=$ 4.17, $p<.05, \eta_{G}^{2}=.04$ (Figures 5A, 5E). However, Using ANCOVA to covary for WISC PRI scores attenuated the main effect of diagnostic group such that it was no longer significant, $F(1,48)=2.52, p=.12$, though further covarying for hearing thresholds decreased the $p$-value slightly, $F(1,45)=3.47, p=.07$. Tb latencies were slightly faster over the left hemisphere than the right, $F(1,49)=4.89, p=.03, \eta_{G}^{2}=.04$. There was no interaction of group and hemisphere, $F(1,49)=0.22, p=.64, \eta_{G}^{2}=.00$.

\section{INSERT FIGURE 6 ABOUT HERE}

\section{Somatosensory P60.}

The amplitude of the somatosensory contralateral (left hemisphere) P60 response was larger in the typically-developing group than the autistic group, $F(1,49)=6.19, p=.02, \eta_{G}^{2}=.11$ (Figures 5B, 5D, 6B). However, using ANCOVA to covary for WISC PRI scores attenuated this main effect of diagnostic group such that it was no longer quite significant, $F(1,48)=3.99, p>$ .05. Covarying for tactile static detection thresholds in participants with those data had little further effect, $F(1,44)=3.45, p=.07$. There was no effect of diagnostic group on the latency of the P60, $F(1,49)=0.41, p=.52, \eta_{G}^{2}=.01($ Figures $5 B, 5 F)$.

\section{ERP - Psychophysical Correlations}

\section{Auditory Tb.}

Unexpectedly, in the ASD group, we observed a significant negative correlation between auditory $\mathrm{Tb}$ amplitudes and pure tone average hearing thresholds collapsed across both ears, 
$r(29)=-.43$, Holm-Bonferroni corrected $p=.04$ (Figure 7A): that is, autistic individuals with larger (more negative) Tb responses had reduced hearing acuity/higher thresholds.

\section{INSERT FIGURE 7 ABOUT HERE}

Due to the unexpected nature of this effect, we carried out an unplanned analysis to explore whether motor confounds could have accounted for it. However, after removal of an outlier, we found no correlation between $\mathrm{Tb}$ amplitudes and participants' median reaction times to auditory stimuli in the ERP task, $r(30)=-.15, p=.42$.

\section{Somatosensory P60}

There was no association between contralateral P60 amplitudes and tactile static detection (Von Frey hair) thresholds, $r(29)=-.06$, uncorrected $p=.76$ (Figure $7 B$ ), nor was there an association between P60 amplitudes and tactile spatial resolution thresholds, $r(30)=.09$, uncorrected $p=.61$ (Figure 7C).

\section{ERP - Questionnaire Correlations}

We found no significant correlations between auditory $\mathrm{Tb}$ amplitudes and auditory scores on either the AASP, SP, or SEQ, or between somatosensory P60 amplitudes and tactile scores on either the AASP, SP, or SEQ, all Holm-Bonferroni corrected $p \geq .37$.

\section{Discussion}

The present study examined sensory processing in young autistic adolescents, as well as a TD comparison group, using multiple measurement modalities: questionnaires, psychophysical thresholds, and event-related potentials. Briefly, we found autistic participants were reported to display more atypical and intense sensory behaviours across almost all questionnaire subscales; however, there was much more limited evidence of group differences in psychophysical thresholds. While there was a trending group difference in hearing acuity, apparently driven by the left ear, there were no group differences in tactile static detection or tactile spatial resolution 
thresholds. Autistic participants appeared to have slower auditory $\mathrm{Tb}$ latencies and reduced somatosensory P60 amplitudes, although these effects were only trending after covarying for WISC PRI cognitive scores and psychophysical thresholds in each modality.

The present study also examined convergence among these measures in the ASD group. We found no associations between questionnaire scores and either psychophysical thresholds or ERP amplitudes. However, we were surprised to observe a significant negative correlation between auditory $\mathrm{Tb}$ amplitudes and hearing thresholds, such that participants with reduced hearing acuity displayed larger neural responses to the noise bursts presented in our ERP task.

\section{Questionnaires}

Our overall finding that the autistic participants reportedly displayed more atypical and intense sensory behaviour on most questionnaire subscales/factors, compared to typicallydeveloping participants, is quite consistent with prior research (e.g., $(15,103,104))$ and with Hypothesis 1. This finding also emphasizes the extent and importance of atypical autistic sensory behaviours in participants' real-world environments.

Indeed, the only subscale from the SEQ, SP, or AASP that did not discriminate between groups in the present study was the AASP Sensation Seeking scale. However, autistic participants were reported to engage in more SP Sensation Seeking behaviour than typicallydeveloping participants and displayed more Sensory Interests/Repetitions/Seeking (SIRS) on the SEQ. Interestingly, in some prior studies using the AASP, autistic participants have even reported engaging in less sensation seeking behaviour than typically-developing individuals $(18,105)$. Elwin and colleagues (106) explain these results by noting that sensation seeking items on the AASP, which were developed for the general population (e.g., "I touch others when I'm talking," "I choose to engage in physical activities"), may not capture the sorts of sensation seeking behaviours preferred by autistic people. This appears to be the most plausible 
explanation for the present study's lack of group differences in AASP Sensation Seeking. As the AASP is not equivalent to the SP or SEQ, and as prior research supports the validity of selfreport sensory measures in ASD (66), the fact the AASP was completed by participants themselves rather than by their caregivers seems unlikely to have been responsible.

Overall, it is striking that many of the largest ASD-TD group differences, as indexed by the Cliff's $\delta$ effect size metric (see Table 3), were observed on the SEQ - a measure that was specifically developed with autism in mind $(14,15)$. These larger effect sizes were obtained on the SEQ even though the SP contains social/emotional items that could exaggerate sensory differences by confounding them with differences in autistic social behaviour (16). It thus seems reasonable to suggest that the SEQ items are better at capturing atypical autistic sensory behaviour than those of the AASP and SP. This appears to encourage the use of sensory measures developed for autistic populations in assessments of autistic people's sensory processing.

\section{Psychophysical Measures}

As predicted by Hypothesis 2, the ASD and TD group did not significantly differ in any of the three psychophysical threshold measures collected in the present study. It is possible that more robust group differences could be observed using measures of stimulus discomfort, such as Loudness Discomfort Levels (see (35)), rather than measures of stimulus detection and discrimination.

However, although we did not observe significant group differences, we did find a strong trend towards group differences in hearing acuity when we used a permutation test to search for effects across both ears and all frequencies. Examination of PTA thresholds from each ear suggests this effect was driven by non-significantly lower thresholds - i.e., higher acuity - in left ear in the ASD group. 
Some caution should be exercised in the interpretation of this result. As noted earlier, the effect did not attain statistical significance. It is also unclear whether it reflects genuine differences in hearing acuity, as opposed to factors such as fatigue or attention to task, which might be particularly important in child samples. The left ear was always tested first, before the right ear, so it is possible that some autistic participants were initially slightly more attentive to the task but that this attention difference had lapsed by the second half of the testing session.

\section{Psychophysical Correlations with Questionnaires.}

Moreover, in the ASD group, psychophysical thresholds were not related to questionnaire scores representing "low thresholds" or enhanced perception. This result suggests that any potential ASD-TD psychophysical threshold differences are unlikely to account for the sensory challenges experienced by many autistic people in their daily lives.

\section{Event-Related Potentials}

As predicted by Hypothesis 3, we observed reduced ERP amplitudes and delayed ERP latencies in ASD relative to TD. Specifically, the amplitudes of the somatosensory P60 response were reduced in ASD and the latency of the auditory Tb was delayed. These ERP group differences were attenuated above thresholds for statistical significance when we covaried for WISC PRI cognitive scores and sensory thresholds; however, the group differences remained as strong trends. It should be noted that much of the variance associated with WISC PRI scores was also associated with diagnostic group (see Table 1), which makes it difficult to interpret the results of this ANCOVA. Therefore, while we cannot definitively state that observed differences in somatosensory P60 amplitudes and auditory Tb latencies are driven by diagnostic group, we believe that they are likely to indeed be driven by diagnostic group.

A number of potential mechanisms could account for group differences in somatosensory P60 amplitudes. Although some theories suggest autistic sensory processing is characterized by 
increased noise (107), we believe the present study's use of mean amplitude measures should make results robust to inter-trial amplitude variability relative to if peak-based measures had been used (100), although intra-trial latency variability could potentially influence results if some responses were partly outside our measurement window. Gaetz and colleagues (108) do speculate that attenuated early somatosensory responses in ASD might reflect reduced GABAergic signalling, which is an intriguing possibility in light of research regarding tactile processing and excitatory and inhibitory neurotransmission in autism $(31,109)$. That said, it is not clear that autistic and typically-developing individuals differ in levels of GABA or glutamate $(109,110)$. The possibility that heterogeneity within autism could contribute to results must also be borne in mind: it is possible that these ERP results might be driven by subgroups and/or they might reflect different processes in different autistic individuals. As for Tb latency, prior research suggests that variance in auditory M50 latencies in ASD is not tightly coupled with levels of white matter $(111,112)$ but exploratory findings suggest it might be related to GABA levels in some subgroups (112). However, it is unclear whether these conclusions generalize to the $\mathrm{Tb}$ response. Ultimately, further research is required to draw definitive conclusions regarding mechanisms for these amplitude and latency differences.

\section{ERP Correlations with Questionnaires.}

We observed no significant associations between Tb or P60 amplitudes and sensory questionnaire scores from the respective sensory modalities of each ERP response (i.e., auditory and tactile). This might imply that the subjective experience of sensory stimuli in autism is not substantially related to neurophysiological event-related responses to stimuli delivered in a controlled laboratory environment. While prior studies such as those of Donkers et al. (68) and Dwyer et al. (55) have found relationships between auditory ERPs and sensory questionnaire scores, both Donkers et al. and Dwyer et al. presented auditory stimuli while participants 
watched quiet videos of personal interest. Thus, it seems possible that neurophysiological responses to sensory stimuli might track better with the daily sensory experiences of autistic individuals if recorded in an experimental paradigm with multiple stimuli competing for attention. However, this does not explain some prior findings of psychophysical-questionnaire associations under more controlled conditions (e.g., $(67,72))$.

\section{ERP Correlations with Psychophysical Thresholds.}

As predicted by Hypothesis 4, somatosensory P60 amplitudes were not related to tactile thresholds. Surprisingly, however, we found a robust correlation between auditory Tb amplitudes and hearing thresholds. Not only was the mere existence of this association contrary to the present study's Hypothesis 4, but the direction of the association suggests that individuals with larger $\mathrm{Tb}$ responses had reduced hearing acuity/higher thresholds.

A number of prior studies investing links between auditory ERP amplitudes and hearing thresholds have done so in populations with hearing loss, and these studies have generally and unsurprisingly found reduced to absent auditory ERP, including oddball ERP, responses in individuals with high hearing thresholds (113-115). In contrast, other studies show enhanced neural responses, potentially attributable to compensatory processing, in individuals with clinically elevated hearing thresholds $(116,117)$. However, the present study was conducted in individuals with normal hearing thresholds, and it is thus unclear whether or not similar compensatory processes can be expected. Fjell and Walhovd (118) did examine auditory N1 responses to auditory tones in three groups of adults, including two groups with normal thresholds $(0-5 \mathrm{~dB}$ and $10-15 \mathrm{~dB})$. Reported N1 amplitudes appeared slightly greater in the $10-15 \mathrm{~dB}$ threshold group, but this effect did not attain significance.

An alternative explanation for the larger $\mathrm{Tb}$ responses observed in autistic participants with higher hearing thresholds from the present study is that these might have reflected the 
influence of the RT task. Participants were instructed to respond rapidly to all events (without discrimination), and it is possible that participants with lower thresholds were able to more quickly accumulate sufficient evidence to initiate a motor response, whereas participants with higher thresholds might have had to build and maintain representations of sensory events over a longer period of time. Unfortunately, owing to the developmental transition in morphologies of earlier vertex auditory ERPs observable in participants in this age range (such that the auditory P1 of some participants has similar timing and topography to the central N1 of others), it was not possible to evaluate whether similar effects could be observed at these latencies.

Given the lack of convergence between questionnaire scores and either ERP amplitudes or psychophysical thresholds, it seems unlikely that neural hyper-responsiveness to sound in autistic people with high hearing thresholds accounts for many of autistic people's real-world sensory challenges. However, this neural hyper-responsiveness could still have important methodological implications. Simply ensuring that all participants have clinically normal hearing levels may not be sufficient to prevent differences in hearing thresholds from confounding results of between-group auditory ERP studies. In the present study, when we covaried for both auditory thresholds and WISC PRI scores in our ERP analyses, a group difference we had previously observed in auditory $\mathrm{Tb}$ amplitudes largely disappeared.

\section{Limitations}

Although the present study has a number of strengths, including the large number of tools in different measurement modalities (questionnaire, neurophysiological, and psychophysical) used to explore sensory processing, the relatively narrow age range of the participants, and the well-characterized nature of the sample, the study is not without limitations.

One notable limitation is that the autistic and typically-developing samples are most likely not from otherwise equivalent populations. There are large ASD-TD differences in 
cognitive ability (see Table 1), with typically-developing participants often showing unexpectedly high scores relative to population norms. This might be because autistic participants were recruited from a broad geographical region, whereas typically-developing participants were largely recruited from the immediate environs of Davis, CA. Davis is an unrepresentative community, with unusually high educational attainments (119). We did not collect information regarding socioeconomic status or parental education levels, and are therefore unable to determine whether and how these factors might have influenced group comparisons. Furthermore, although we attempted to use ANCOVA to determine whether significant group differences might be explained by cognitive abilities, we acknowledge that this procedure has limitations; it is difficult in the present sample to separate variance associated with cognitive ability from variance associated with diagnosis. Fortunately, we believe the main contribution of the present study consists in its examination of convergence between different types of measures in ASD, rather than ASD-TD group differences in specific measures, making this limitation of arguably secondary importance.

We also chose to focus our analyses on the auditory $\mathrm{Tb}$ and the somatosensory P60. These were selected to minimize multiple comparisons and because they were the first large and developmentally stable cortical responses clearly visible in ERP averages (the morphology of earlier auditory responses changes dramatically in this age range, creating problems of overlap and cancellation across participants). However, we recognize that the $\mathrm{Tb}$ and $\mathrm{P} 60$ responses are only a relatively small part of the neurophysiological responses to these stimuli.

Another limitation of the present study is that auditory ERPs were recorded in response to broad band stimuli, whereas psychophysical thresholds were measured in response to pure tones. 
This may complicate interpretation of the correlation between $\mathrm{Tb}$ amplitudes and hearing thresholds.

The present study sample is also drawn from a relatively limited range of the autistic population. Due to a recruitment restriction which made collection of self-report and laboratory task measures easier, participants almost universally did not have intellectual disabilities. Few female and no nonbinary participants were recruited. Due to another recruitment restriction intended to minimize variance associated with developmental change, a limited age range (1114) was used. While the narrowness of this sample has some advantages, it reduces the generalizability of these results.

\section{Conclusions}

The present study provides a rigorous multidimensional examination of sensory processing in ASD, using neurophysiological, psychophysical, self-report, and parent-report measures. The most robust group differences were observed on questionnaire measures, which may therefore have particular value in identifying sensory challenges and discomfort in community settings. The SEQ, a measure designed for autism, appeared to perform particularly well, emphasizing the advantages of using measures designed with autistic sensory phenotypes in mind. We observed no group differences in psychophysical thresholds, and a nonsignificant trend towards lower auditory thresholds in ASD from the left ear might reflect attentional or other processes rather than acuity per se. We observed no associations between sensory acuity and questionnaire measures.

We also observed some group differences in ERP measures. Although findings of attenuated somatosensory P60 amplitudes and delayed auditory Tb latencies in the ASD group were no longer significant after correlating for cognitive ability, they remained as strong trends, and might reflect genuine group differences. Furthermore, in the ASD group, we observed a 
correlation between auditory $\mathrm{Tb}$ amplitudes and auditory thresholds, such that participants with higher auditory thresholds/reduced acuity had larger Tb responses to auditory stimuli. This effect might reflect loudness recruitment or efficiency of neural processing, but replication and further research will be important to fully understand this effect and its methodological implications. 


\section{Declarations}

\section{Ethics approval and consent to participate}

The study was approved by the UC Davis Institutional Review Board and all procedures were in accordance with the Declaration of Helsinki. Caregivers of participants consented, and participants assented, to participation in this study.

\section{Availability of data and materials}

The datasets generated and/or analysed during the current study are not publicly available but are available from the corresponding author on reasonable request.

\section{Competing interests}

None of the authors have competing financial interests relevant to this work.

\section{Funding}

This work was supported by an investigator initiated pilot grant from the UC Davis MIND Institute, pilot grant research funding from Autism Speaks, NIMH 1 R21 MH086854, and gift funds from the Robert Shoes Fund all to CDS, a UC Davis Deans' Distinguished Graduate Fellowship to PD, and support for PD from an Autism Center of Excellence grant awarded by the NICHD (P50 HD093079). Apart from the UC Davis MIND Institute (a research center at which this work was partly conducted), none of the funders had any role in collection, analysis, or interpretation of the data.

\section{Authors' contributions}

The present study was designed by SMR, CDS, and YT. YT, IZ, SMR, and CDS contributed to data collection and processing. PD analyzed the data and drafted this manuscript, which was read, edited, and approved by all authors.

\section{Acknowledgements}

We wish to gratefully acknowledge all of the children and families who generously devoted considerable time and effort to participating in this study. We thank David Horton for 
instrumentation fabrication, Dr. Andrea Schneider for participant neuropsychological assessments, Manish Saggar, PhD for software development, Margarita Beransky and Ashley Stark for protocol development, Fernanda Vieira, Sarah Huffman, Ryan Hubbard, Hilda Zamora Hursh, and Antoinette O'Neill for study coordination, data collection and processing. We thank Joshua Martin and Nancy Huynh for additional data processing. 


\section{Tables}

Table 1. Characteristics of autistic and typically-developing participants. Mean and standard deviation $(S D)$ are given on each metric, along with minimum and maximum scores. The numbers of participants in each group with available data on each metric are also reported. Where measures were collected from participants in both the ASD and TD groups, WilcoxonMann-Whitney rank-sum tests are used to compare scores across groups; $\delta$ (Cliff, 1993) is reported as an effect size. ADI-R scores are based on the diagnostic algorithm, not the current behaviour algorithm.

For reference, ASD cut-offs are 15 on the SCQ total score, 4 on the ADOS Calibrated Severity Scores (CSS), 10 on the ADI-R Social Interaction score, 8 on the ADI-R Communication score (for verbal participants like those in the present study), and 3 on the ADI-R "Restricted and Repetitive Behaviors" score (Berument et al., 1999; Gotham et al., 2009; Lord et al., 1994). The developers of the ASSQ parent-report form recommend 13 as a sensitive cut-off score and 19 as a specific cut-off score (Ehlers et al., 1999).

\begin{tabular}{|c|c|c|c|c|c|c|c|c|}
\hline & \multicolumn{3}{|c|}{ ASD } & \multicolumn{3}{|c|}{ TD } & \multirow[t]{2}{*}{$p$} & \multirow[t]{2}{*}{$\delta$} \\
\hline & $\begin{array}{l}\text { Mean } \\
\text { (SD) }\end{array}$ & Range & $n$ & $\begin{array}{l}\text { Mean } \\
\text { (SD) }\end{array}$ & Range & $n$ & & \\
\hline $\begin{array}{l}\text { Chronological Age } \\
\text { (years) }\end{array}$ & $\begin{array}{l}12.73 \\
(1.17)\end{array}$ & $\begin{array}{l}11.05- \\
14.97\end{array}$ & 46 & $\begin{array}{l}13.04 \\
(0.93)\end{array}$ & $\begin{array}{l}11.57- \\
14.72\end{array}$ & 21 & .24 & -.18 \\
\hline $\begin{array}{l}\text { WISC Full-Scale IQ } \\
\text { (FSIQ) }\end{array}$ & $\begin{array}{l}97.37 \\
(18.26)\end{array}$ & $\begin{array}{l}60- \\
125\end{array}$ & 46 & $\begin{array}{l}122.14 \\
(11.09)\end{array}$ & $\begin{array}{l}91- \\
139\end{array}$ & 21 & $<.0001$ & -.76 \\
\hline $\begin{array}{l}\text { WISC Verbal } \\
\text { Comprehension } \\
\text { Index (VCI) }\end{array}$ & $\begin{array}{l}100.89 \\
(19.71)\end{array}$ & $\begin{array}{l}59- \\
134\end{array}$ & 46 & $\begin{array}{l}126.24 \\
(11.62)\end{array}$ & $\begin{array}{l}99- \\
152\end{array}$ & 21 & $<.0001$ & -.74 \\
\hline $\begin{array}{l}\text { WISC Perceptual } \\
\text { Reasoning Index } \\
\text { (PRI) }\end{array}$ & $\begin{array}{l}106.33 \\
(16.33)\end{array}$ & $\begin{array}{l}67- \\
143\end{array}$ & 46 & $\begin{array}{l}120.52 \\
(15.21)\end{array}$ & $\begin{array}{l}84- \\
141\end{array}$ & 21 & .001 & -.50 \\
\hline $\begin{array}{l}\text { WISC Working } \\
\text { Memory Index } \\
\text { (WMI) }\end{array}$ & $\begin{array}{l}92.70 \\
(16.72)\end{array}$ & $\begin{array}{l}52- \\
126\end{array}$ & 46 & $\begin{array}{l}108.33 \\
(10.19)\end{array}$ & $\begin{array}{l}91- \\
126\end{array}$ & 21 & $<.0001$ & -.61 \\
\hline $\begin{array}{l}\text { WISC Processing } \\
\text { Speed Index (PSI) }\end{array}$ & $\begin{array}{l}86.46 \\
(16.40)\end{array}$ & $\begin{array}{l}53- \\
126\end{array}$ & 46 & $\begin{array}{l}107.62 \\
(11.87)\end{array}$ & $\begin{array}{l}91- \\
131\end{array}$ & 21 & $<.0001$ & -.70 \\
\hline SCQ Total & $\begin{array}{l}22.51 \\
(5.29)\end{array}$ & $11-35$ & 43 & $\begin{array}{l}1.10 \\
(1.55)\end{array}$ & $0-5$ & 21 & $<.0001$ & 1.00 \\
\hline ASSQ Total & \begin{tabular}{|l|}
29.48 \\
$(8.43)$
\end{tabular} & $12-45$ & 42 & $\begin{array}{l}1.00 \\
(1.73)\end{array}$ & $0-7$ & 21 & $<.0001$ & 1.00 \\
\hline ADOS Total CSS & $\begin{array}{l}6.66 \\
(1.72)\end{array}$ & $3-10$ & 44 & - & - & 0 & - & - \\
\hline
\end{tabular}




\begin{tabular}{|l|l|l|l|l|l|l|l|l|}
\hline $\begin{array}{l}\text { ADOS Social Affect } \\
\text { CSS }\end{array}$ & $\begin{array}{l}6.25 \\
(1.99)\end{array}$ & $3-10$ & 44 & - & - & 0 & - & - \\
\hline $\begin{array}{l}\text { ADOS "Restricted } \\
\text { and Repetitive } \\
\text { Behaviors" CSS }\end{array}$ & $\begin{array}{l}7.41 \\
(2.33)\end{array}$ & $1-10$ & 44 & - & - & 0 & - & - \\
\hline $\begin{array}{l}\text { ADI-R Social } \\
\text { Interaction }\end{array}$ & $\begin{array}{l}20.82 \\
(4.19)\end{array}$ & $13-30$ & 38 & - & - & 0 & - & - \\
\hline $\begin{array}{l}\text { ADI-R } \\
\text { Communication }\end{array}$ & $\begin{array}{l}17.61 \\
(3.82)\end{array}$ & $7-25$ & 38 & - & - & 0 & - & - \\
\hline $\begin{array}{l}\text { ADI-R "Restricted } \\
\text { and Repetitive } \\
\text { Behaviors" }\end{array}$ & $\begin{array}{l}7.95 \\
(2.23)\end{array}$ & $4-12$ & 38 & - & - & 0 & - & - \\
\hline
\end{tabular}




\begin{tabular}{|c|c|c|c|c|c|c|c|c|c|c|c|c|}
\hline & \multicolumn{6}{|c|}{ Retained Trials } & \multicolumn{6}{|c|}{ Rejected Trials } \\
\hline & \multicolumn{2}{|c|}{ ASD } & \multicolumn{2}{|c|}{ TD } & \multirow[t]{2}{*}{$p$} & \multirow[t]{2}{*}{$\delta$} & \multicolumn{2}{|c|}{ ASD } & \multicolumn{2}{|c|}{ TD } & \multirow[t]{2}{*}{$p$} & \multirow[t]{2}{*}{$\delta$} \\
\hline & $\begin{array}{c}\text { Mean } \\
(\mathrm{SD})\end{array}$ & Range & $\begin{array}{c}\text { Mean } \\
(\mathrm{SD})\end{array}$ & Range & & & $\begin{array}{c}\text { Mean } \\
(\mathrm{SD})\end{array}$ & Range & $\begin{array}{c}\text { Mean } \\
(\mathrm{SD})\end{array}$ & $\begin{array}{c}\text { Mean } \\
(\mathrm{SD})\end{array}$ & & \\
\hline $\mathrm{A}$ & $\begin{array}{l}87.67 \\
(21.89)\end{array}$ & $48-132$ & \begin{tabular}{|l|}
98.94 \\
$(21.74)$
\end{tabular} & $49-134$ & .08 & -.30 & $\begin{array}{l}42.00 \\
(21.49)\end{array}$ & $5-81$ & $\begin{array}{l}32.61 \\
(20.91)\end{array}$ & $6-76$ & .15 & .25 \\
\hline $\mathrm{S}$ & $\begin{array}{l}86.30 \\
(21.55)\end{array}$ & $53-128$ & $\begin{array}{l}99.44 \\
(15.49)\end{array}$ & $71-124$ & .02 & -.39 & $\begin{array}{l}42.97 \\
(22.90)\end{array}$ & $10-82$ & $\begin{array}{l}31.61 \\
(17.18)\end{array}$ & $10-69$ & .08 & .30 \\
\hline
\end{tabular}


Table 3. Results of statistical comparisons of autistic and typically-developing groups on SP, AASP, and SEQ scores. Results of ordinal Wilcoxon-Mann-Whitney tests are presented on the left, along with associated Cliff's $\delta$ effect sizes. Lower scores on SP and higher scores on AASP and SEQ indicate greater levels of sensory patterns on each subscale. Thus, negative $\delta$ for SP and positive $\delta$ for AASP and SEQ indicate greater levels of sensory patterns in the ASD group than the TD group. Results of ANCOVA analyses covarying for WISC PRI scores are presented on the right. Corrected $p$-values employ the Holm-Bonferroni procedure to correct for seventeen comparisons (the total number of subscales across all three questionnaires), separately for ordinal and ANCOVA analyses.

\begin{tabular}{|c|c|c|c|c|c|c|}
\hline & \multicolumn{3}{|c|}{ Wilcoxon-Mann-Whitney Effect } & \multicolumn{3}{|c|}{ ANCOVA Effect } \\
\hline & Cliff's $\delta$ & $p$ & $\begin{array}{c}\text { Corrected } \\
p\end{array}$ & $F$ & $p$ & $\begin{array}{c}\text { Corrected } \\
p\end{array}$ \\
\hline $\begin{array}{l}\text { SP Sensation } \\
\text { Seeking }\end{array}$ & -.82 & $<.0001$ & $<.0001$ & 27.64 & $<.0001$ & $<.0001$ \\
\hline $\begin{array}{l}\text { SP Emotionally } \\
\text { Reactive }\end{array}$ & -.78 & $<.0001$ & $<.0001$ & 30.35 & $<.0001$ & $<.0001$ \\
\hline $\begin{array}{l}\text { SP Low } \\
\text { Endurance/Tone }\end{array}$ & -.63 & .0001 & .0006 & 10.62 & .002 & .006 \\
\hline $\begin{array}{l}\text { SP Oral Sensory } \\
\text { Sensitivity }\end{array}$ & -.76 & $<.0001$ & $<.0001$ & 24.02 & $<.0001$ & $<.0001$ \\
\hline $\begin{array}{l}\text { SP Inattention/ } \\
\text { Distractibility }\end{array}$ & -.88 & $<.0001$ & $<.0001$ & 61.63 & $<.0001$ & $<.0001$ \\
\hline SP Poor Registration & -.80 & $<.0001$ & $<.0001$ & 27.69 & $<.0001$ & $<.0001$ \\
\hline $\begin{array}{l}\text { SP Sensory } \\
\text { Sensitivity }\end{array}$ & -.46 & .004 & .009 & 7.48 & .009 & .02 \\
\hline SP Sedentary & -.61 & .0002 & .0007 & 14.96 & .0003 & .002 \\
\hline $\begin{array}{l}\text { SP Fine } \\
\text { Motor/Perceptual }\end{array}$ & -.70 & $<.0001$ & .0001 & 12.47 & .0009 & .004 \\
\hline $\begin{array}{l}\text { AASP Low } \\
\text { Registration }\end{array}$ & .79 & $<.0001$ & $<.0001$ & 22.08 & $<.0001$ & .0002 \\
\hline $\begin{array}{l}\text { AASP Sensory } \\
\text { Sensitivity }\end{array}$ & .73 & $<.0001$ & .0001 & 21.69 & $<.0001$ & .0002 \\
\hline $\begin{array}{l}\text { AASP Sensation } \\
\text { Avoiding }\end{array}$ & .72 & $<.0001$ & .0001 & 14.45 & .0004 & .002 \\
\hline $\begin{array}{l}\text { AASP Sensation } \\
\text { Seeking }\end{array}$ & .00 & .98 & .98 & 0.00 & .99 & .99 \\
\hline SEQ HYPO & .83 & $<.0001$ & $<.0001$ & 27.25 & $<.0001$ & $<.0001$ \\
\hline SEQ HYPER & .92 & $<.0001$ & $<.0001$ & 61.71 & $<.0001$ & $<.0001$ \\
\hline
\end{tabular}




\begin{tabular}{|l|l|l|l|l|l|l|}
\hline SEQ SIRS & .98 & $<.0001$ & $<.0001$ & 86.31 & $<.0001$ & $<.0001$ \\
\hline SEQ EP & .96 & $<.0001$ & $<.0001$ & 66.23 & $<.0001$ & $<.0001$ \\
\hline
\end{tabular}




\section{Figure Captions}

Figure 1. 12-yr child pilot participant seated at the tri-sensory stimulation desktop.

Figure 2. Raw Sensory Profile (SP) scores (panel A, top), Adolescent-Adult Sensory Profile (AASP) scores (panel B, bottom left), and Sensory Experiences Questionnaire-3.0 (SEQ-3.0) scores (panel $C$, bottom right) in the autistic and typically-developing groups. Groups significantly differed in all patterns except AASP Sensation Seeking (see Table 3). Lower scores on SP and higher scores on AASP and SEQ indicates greater levels of sensory patterns on each subscale.

Figure 3. Hearing acuity in each group. No statistically reliable group differences were observed, despite the apparent trend towards greater auditory acuity in the ASD group in the left ear (panel $B)$.

Top panel, A: Hearing thresholds for each tone frequency and ear separately.

Bottom panels, $B-C$ : Pure tone average thresholds (collapsing across frequencies) for each ear.

Figure 4. Tactile thresholds in each group.

Left panel, $A$ : Thresholds for detection of static (non-vibrating) tactile stimuli, specifically Von Frey hairs, using an approximate/theoretical log scale of forces provided by the manufacturer (Stoelting Co., 2001).

Right panel, $B$ : Thresholds for recognition of the orientations of tactile gratings of different widths (in mm). 
Figure 5. Plots depicting Auditory Tb and somatosensory P60 ERP responses.

Top (panels $A-B$ ): Tb and P60 ERP waveforms in each group. P60 responses are contralateral (left hemisphere only), but the $\mathrm{Tb}$ is shown over each hemisphere. The gray highlighted regions represent the measurement windows (Tb: 135 - $195 \mathrm{~ms}$, P60: 38 - $78 \mathrm{~ms}$ ).

Middle (panels $C-D$ ): Boxplots showing amplitudes of the Tb and P60 ERP responses.

Amplitudes of both were greater in TD then ASD, but these effects dropped below the threshold for statistical significance after covarying for WISC PRI scores. Tb amplitudes were larger over the left hemisphere than the right.

Bottom (panels $E-F$ ): Boxplots showing latencies of the Tb and P60 ERP responses. Latencies of the auditory $\mathrm{Tb}$ were faster in $\mathrm{TD}$ than $\mathrm{ASD}$, but this effect was no longer significant after covarying for WISC PRI scores. Tb latencies were faster over the left hemisphere than the right.

Figure 6. Panel A, left: Splined scalp topographies over the left and right hemispheres in the time window of the auditory $\mathrm{Tb}$ response $(135-195 \mathrm{~ms})$. Electrodes used to the measure the $\mathrm{Tb}$ response are highlighted in magenta. Note that electrode positions are based on observations from a Polhemus digitizer and may appear slightly irregular as a result. Panel $B$, right: Splined scalp topographies over the left (contralateral) hemisphere in the time window of the somatosensory P60 response $(38-78 \mathrm{~ms})$. Electrodes used to the measure the P60 response are highlighted in blue. 
Figure 7. Panel A, left: A negative correlation was observed between auditory Tb amplitudes (averaged across hemispheres) and pure tone average hearing thresholds (averaged across ears), corrected $p=.04$. Despite the apparent outliers, the corrected $p$-value remained significant when the association was measured ordinally (using Kendall's $\tau$ ).

Panel $B$, centre: No association between contralateral somatosensory P60 amplitudes and tactile static detection (Von Frey hair) thresholds was observed.

Panel $C$, right: No association between somatosensory P60 amplitudes and tactile spatial resolution (JVP dome) thresholds was observed. 


\section{References}

1. Baranek GT. Autism during infancy: A retrospective video analysis of sensory-motor and social behaviors at 9-12 months of age. J Autism Dev Disord. 1999;29(3):213-24.

2. Baranek GT, Woynaroski TG, Nowell S, Turner-Brown L, DuBay M, Crais ER, et al. Cascading effects of attention disengagement and sensory seeking on social symptoms in a community sample of infants at-risk for a future diagnosis of autism spectrum disorder. Dev Cogn Neurosci. 2018;29:30-40.

3. Damiano-Goodwin CR, Woynaroski TG, Simon DM, Ibañez L V., Murias M, Kirby A, et al. Developmental sequelae and neurophysiologic substrates of sensory seeking in infant siblings of children with autism spectrum disorder. Dev Cogn Neurosci. 2018;29:41-53.

4. Kolesnik A, Ali JB, Gliga T, Guiraud J, Charman T, Jones EJH. Increased cortical reactivity to repeated tones at 8 months in infants with later ASD. Transl Psychiatry. 2019;9:46.

5. Lin L-Y, Huang P-C. Quality of life and its related factors for adults with autism spectrum disorder. Disabil Rehabil. 2019;41(8):896-903.

6. McConachie H, Wilson C, Mason D, Garland D, Parr JR, Rattazzi A, et al. What is important in measuring quality of life? Reflections by autistic adults in four countries. Autism in Adulthood. 2020;2(1):4-12.

7. Ismael N, Lawson LM, Hartwell J. Relationship between sensory processing and participation in daily occupations for children with autism spectrum disorder: A systematic review of studies that used Dunn's sensory processing framework. Am J Occup Ther. 2018;72(3):7203205030.

8. Little LM, Ausderau K, Sideris J, Baranek GT. Activity participation and sensory features among children with autism spectrum disorders. J Autism Dev Disord. 2015;45(9):2981- 
90.

9. Green SA, Ben-Sasson A, Soto TW, Carter AS. Anxiety and sensory over-responsivity in toddlers with autism spectrum disorders: Bidirectional effects across time. J Autism Dev Disord. 2012;42(6):1112-9.

10. Neil L, Olsson NC, Pellicano E. The relationship between intolerance of uncertainty, sensory sensitivities, and anxiety in autistic and typically developing children. J Autism Dev Disord. 2016;46(6):1962-73.

11. Reynolds S, Lane SJ, Thacker L. Sensory processing, physiological stress, and sleep behaviors in children with and without autism spectrum disorders. Occup Particip Heal. 2012;32(1):246-57.

12. Tzischinsky O, Meiri G, Manelis L, Bar-Sinai A, Flusser H, Michaelovski A, et al. Sleep disturbances are associated with specific sensory sensitivities in children with autism. Mol Autism. 2018;9(1):22.

13. Lewis CR, Taguinod F, Jepsen WM, Cohen J, Agrawal K, Huentelman MJ, et al. Telomere length and autism spectrum disorder within the family: Relationships with cognition and sensory symptoms. Autism Res. 2020; 13(7): 1094-1101

14. Ausderau K, Sideris J, Furlong M, Little LM, Bulluck J, Baranek GT. National survey of sensory features in children with ASD: Factor structure of the sensory experience questionnaire (3.0). J Autism Dev Disord. 2014;44(4):915-25.

15. Baranek GT, David FJ, Poe MD, Stone WL, Watson LR. Sensory Experiences Questionnaire: Discriminating sensory features in young children with autism, developmental delays, and typical development. J Child Psychol Psychiatry Allied Discip. 2006;47(6):591-601. 
16. Kientz MA, Dunn W. A comparison of the performance of children with and without autism on the Sensory Profile. Am J Occup Ther. 1997;51(7):530-7.

17. Tomchek SD, Dunn W. Sensory processing in children with and without autism: A comparative study using the Short Sensory Profile. Am J Occup Ther. 2007;61(2):190200.

18. Crane L, Goddard L, Pring L. Sensory processing in adults with autism spectrum disorders. Autism. 2009;13(3):215-28.

19. Takayama Y, Hashimoto R, Tani M, Kanai C, Yamada T, Watanabe H, et al. Standardization of the Japanese version of the Glasgow Sensory Questionnaire (GSQ). Res Autism Spectr Disord. 2014;8(4):347-53.

20. Tavassoli T, Hoekstra RA, Baron-Cohen S. The Sensory Perception Quotient (SPQ): Development and validation of a new sensory questionnaire for adults with and without autism. Mol Autism. 2014;5(1):29.

21. DeBoth KK, Reynolds S. A systematic review of sensory-based autism subtypes. Res Autism Spectr Disord. 2017;36:44-56.

22. Elwin M, Schröder A, Ek L, Wallsten T, Kjellin L. Sensory clusters of adults with and without autism spectrum conditions. J Autism Dev Disord. 2017;47(3):579-89.

23. Boyd BA, Baranek GT, Sideris J, Poe MD, Watson LR, Patten E, et al. Sensory features and repetitive behaviors in children with autism and developmental delays. Autism Res. 2010;3:78-87.

24. Kuiper MWM, Verhoeven EWM, Geurts HM. The Dutch Glasgow Sensory Questionnaire: Psychometric properties of an autism-specific sensory sensitivity measure. Autism. 2019;23(4):922-32. 
25. Linke AC, Jao Keehn RJ, Pueschel EB, Fishman I, Müller RA. Children with ASD show links between aberrant sound processing, social symptoms, and atypical auditory interhemispheric and thalamocortical functional connectivity. Dev Cogn Neurosci. 2018;29:117-26.

26. Cascio C, McGlone F, Folger S, Tannan V, Baranek G, Pelphrey KA, et al. Tactile perception in adults with autism: A multidimensional psychophysical study. J Autism Dev Disord. 2008;38(1):127-37.

27. Fukuyama H, Kumagaya SI, Asada K, Ayaya S, Kato M. Autonomic versus perceptual accounts for tactile hypersensitivity in autism spectrum disorder. Sci Rep 2017;7:8259.

28. Puts NAJ, Wodka EL, Tommerdahl M, Mostofsky SH, Edden RAE. Impaired tactile processing in children with autism spectrum disorder. J Neurophysiol. 2014;111(9):180311.

29. Quinde-Zlibut JM, Okitondo CD, Williams ZJ, Weitlauf A, Mash LE, Heflin BH, et al. Elevated thresholds for light touch in children with autism reflect more conservative perceptual decision-making rather than a sensory deficit. Front Hum Neurosci. 2020;14:122.

30. Blakemore S, Tavassoli T, Calò S, Thomas RM, Catmur C, Frith U, et al. Tactile sensitivity in Asperger syndrome. Brain Cogn. 2006;61:5-13.

31. Sapey-Triomphe L-A, Lamberton F, Sonié S, Mattout J, Schmitz C. Tactile hypersensitivity and GABA concentration in the sensorimotor cortex of adults with autism. Autism Res. 2019;12(4):562-75.

32. Ide M, Yaguchi A, Sano M, Fukatsu R, Wada M. Higher tactile temporal resolution as a basis of hypersensitivity in individuals with autism spectrum disorder. J Autism Dev 
Disord. 2019;49:44-53.

33. Chien YL, Chao CC, Wu SW, Hsueh HW, Chiu YN, Tsai WC, et al. Small fiber pathology in autism and clinical implications. Neurology. 2020;95(19):e2697-706.

34. Demopolous C, Lewine JD. Audiometric profiles in autism spectrum disorders: Does subclinical hearing loss impact communication? Autism Res. 2016;9(1):107-20.

35. Khalfa S, Bruneau N, Rogé B, Georgieff N, Veuillet E, Adrien J-L, et al. Increased perception of loudness in autism. Hear Res. 2004;198(1-2):87-92.

36. Kuiper MWM, Verhoeven EWM, Geurts HM. Stop making noise! Auditory sensitivity in adults with an autism spectrum disorder diagnosis: Physiological habituation and subjective detection thresholds. J Autism Dev Disord. 2019;49:2116-2128.

37. Gravel JS, Dunn M, Lee WW, Ellis MA. Peripheral audition of children on the autistic spectrum. Ear Hear. 2006;27(3):299-312.

38. Bonnel A, McAdams S, Smith B, Berthiaume C, Bertone A, Ciocca V, et al. Enhanced pure-tone pitch discrimination among persons with autism but not Asperger syndrome. Neuropsychologia. 2010;48(9):2465-75.

39. Jones CRG, Happé F, Baird G, Simonoff E, Marsden AJS, Tregay J, et al. Auditory discrimination and auditory sensory behaviours in autism spectrum disorders. Neuropsychologia. 2009;47(13):2850-8.

40. Mayer JL, Hannent I, Heaton PF. Mapping the developmental trajectory and correlates of enhanced pitch perception on speech processing in adults with ASD. J Autism Dev Disord. 2016;46(5):1562-73.

41. Do B, Lynch P, Macris EM, Smyth B, Stavrinakis S, Quinn S, et al. Systematic review and meta-analysis of the association of Autism Spectrum Disorder in visually or hearing 
impaired children. Ophthalmic Physiol Opt. 2017;37(2):212-24.

42. Rydzewska E, Hughes-McCormack LA, Gillberg C, Henderson A, Macintyre C, Rintoul $\mathrm{J}$, et al. Prevalence of sensory impairments, physical and intellectual disabilities, and mental health in children and young people with self/proxy-reported autism:

Observational study of a whole country population. Autism. 2018;23(5):1201-9.

43. Haesen B, Boets B, Wagemans J. A review of behavioural and electrophysiological studies on auditory processing and speech perception in autism spectrum disorders. Res Autism Spectr Disord. 2011;5(2):701-14.

44. O'Connor K. Auditory processing in autism spectrum disorder: A review. Neurosci Biobehav Rev. 2012;36(2):836-54.

45. Williams ZJ, Abdelmessih PG, Key AP, Woynaroski TG. Cortical auditory processing of simple stimuli is altered in autism: A meta-analysis of auditory evoked responses. Biol Psychiatry Cogn Neurosci Neuroimaging. 2021;6(8):767-81.

46. Albrecht R, Suchodoletz W v., Uwer R. The development of auditory evoked dipole source activity from childhood to adulthood. Clin Neurophysiol. 2000;111(12):2268-76.

47. Gilley PM, Sharma A, Dorman M, Martin K. Developmental changes in refractoriness of the cortical auditory evoked potential. Clin Neurophysiol. 2005;116(3):648-57.

48. Ponton C, Eggermont J, Khosla D, Kwong B, Don M. Maturation of human central auditory system activity: Separating auditory evoked potentials by dipole source modeling. Clin Neurophysiol. 2002;113:407-20.

49. Sharma A, Kraus N, McGee TJ, Nicol TG. Developmental changes in P1 and N1 central auditory responses elicited by consonant-vowel syllables. Electroencephalogr Clin Neurophysiol. 1997;104:540-5. 
50. Uppal N, Foxe JJ, Butler JS, Acluche F, Molholm S. The neural dynamics of somatosensory processing and adaptation across childhood: A high-density electrical mapping study. J Neurophysiol. 2016;115(3):1605-19.

51. Eimer M, Maravita A, Van Velzen J, Husain M, Driver J. The electrophysiology of tactile extinction: ERP correlates of unconscious somatosensory processing. Neuropsychologia. 2002;40(13):2438-47.

52. Pratt H. Sensory ERP components. In: Kappenman ES, Luck SJ, editors. The Oxford Handbook of Event-Related Potential Components. 2011.

53. Schubert R, Blankenburg F, Lemm S, Villringer A, Curio G. Now you feel it - now you don't: ERP correlates of somatosensory awareness. Psychophysiology. 2006;43(1):31-40.

54. De Meo-Monteil R, Nordahl CW, Amaral DG, Rogers SJ, Harootonian SK, Martin J, et al. Differential altered auditory event-related potential responses in young boys on the autism spectrum with and without disproportionate megalencephaly. Autism Res. 2019;12(8):1236-50.

55. Dwyer P, Wang X, De Meo-Monteil R, Hsieh F, Saron CD, Rivera SM. Defining clusters of young autistic and typically developing children based on loudness-dependent auditory electrophysiological responses. Mol Autism. 2020;11:48.

56. Roberts TPL, Matsuzaki J, Blaskey L, Bloy L, Edgar JC, Kim M, et al. Delayed M50/M100 evoked response component latency in minimally verbal/nonverbal children who have autism spectrum disorder. Mol Autism. 2019;10:34.

57. Demopoulos C, Yu N, Tripp J, Mota N, Brandes-Aitken AN, Desai SS, et al. Magnetoencephalographic imaging of auditory and somatosensory cortical responses in children with autism and sensory processing dysfunction. Front Hum Neurosci. 
$2017 ; 11: 259$.

58. Marco EJ, Khatibi K, Hill SS, Siegel B, Arroyo MS, Dowling AF, et al. Children with autism show reduced somatosensory response: An MEG study. Autism Res. 2012;5(5):340-51.

59. Russo N, Foxe JJ, Brandwein AB, Altschuler T, Gomes H, Molholm S. Multisensory processing in children with autism: High-density electrical mapping of auditorysomatosensory integration. Autism Res. 2010;3(5):253-67.

60. Uljarević M, Baranek G, Vivanti G, Hedley D, Hudry K, Lane A. Heterogeneity of sensory features in autism spectrum disorder: Challenges and perspectives for future research. Autism Res. 2017;10(5):703-10.

61. Ward J. Individual differences in sensory sensitivity: A synthesising framework and evidence from normal variation and developmental conditions. Cogn Neurosci. 2018;10(3):139-57.

62. Dunn W. The impact of sensory processing abilities on the daily lives of young children and their families: A conceptual model. Infants Young Child. 1997;9(4):23-35.

63. Keehn B, Nair A, Lincoln AJ, Townsend J, Müller RA. Under-reactive but easily distracted: An fMRI investigation of attentional capture in autism spectrum disorder. Dev Cogn Neurosci. 2016;17:46-56.

64. Remington A, Fairnie J. A sound advantage: Increased auditory capacity in autism. Cognition. 2017;166:459-65.

65. Venker CE, Mathée J, Neumann D, Edwards J, Saffran J, Weismer SE. Competing perceptual salience in a visual word recognition task differentially affects children with and without autism spectrum disorder. Autism Res. 2021;14(6):1147-62. 
66. Keith JM, Jamieson JP, Bennetto L. The importance of adolescent self-report in autism spectrum disorder: Integration of questionnaire and autonomic measures. J Abnorm Child Psychol. 2019;47:741-54.

67. Karhson DS, Golob EJ. Atypical sensory reactivity influences auditory attentional control in adults with autism spectrum disorders. Autism Res. 2016;9(10):1079-92.

68. Donkers FCL, Carlson M, Schipul SE, Belger A, Baranek GT. Auditory event-related potentials and associations with sensory patterns in children with autism spectrum disorder, developmental delay, and typical development. Autism. 2020;24(5):1093-110.

69. Chien YL, Hsieh MH, Gau SSF. Mismatch negativity and P3a in adolescents and young adults with autism spectrum disorders: Behavioral correlates and clinical implications. J Autism Dev Disord. 2017;48(5):1684-97.

70. Ludlow A, Mohr B, Whitmore A, Garagnani M, Pulvermüller F, Gutierrez R. Auditory processing and sensory behaviours in children with autism spectrum disorders as revealed by mismatch negativity. Brain Cogn. 2014;86(1):55-63.

71. Hudac CM, DesChamps TD, Arnett AB, Cairney BE, Ma R, Webb SJ, et al. Early enhanced processing and delayed habituation to deviance sounds in autism spectrum disorder. Brain Cogn. 2018;123:110-9.

72. Cascio CJ, Gu C, Schauder KB, Key AP, Yoder P. Somatosensory event-related potentials and association with tactile behavioral responsiveness patterns in children with ASD. Brain Topogr. 2015;28(6):895-903.

73. Wechsler D. The Wechsler Intelligence Scale for Children. 4th ed. San Antonio: Psychological Corporation; 2003.

74. Nader A-M, Jelenic P, Soulières I. Discrepancy between WISC-III and WISC-IV 
cognitive profile in autism spectrum: What does it reveal about autistic cognition? PLoS One. 2015;10(12):e0144645.

75. Nader AM, Courchesne V, Dawson M, Soulières I. Does WISC-IV underestimate the intelligence of autistic children? J Autism Dev Disord. 2016;46(5):1582-9.

76. Lord C, Risi S, Linda L, Cook Jr. EH, Leventhal, Bennett L, DiLavore PC, et al. The Autism Diagnostic Observation Schedule - Generic: A standard measure of social and communication deficits associated with the spectrum of autism. J Autism Dev Disord. 2000;30(3):205-23.

77. Gotham K, Risi S, Pickles A, Lord C. The Autism Diagnostic Observation Schedule: Revised algorithms for improved diagnostic validity. J Autism Dev Disord. 2007;37(4):613-27.

78. Hus V, Lord C. The Autism Diagnostic Observation Schedule, module 4: Revised algorithm and standardized severity scores. J Autism Dev Disord. 2014;44(8):1996-2012.

79. Berument SK, Rutter M, Lord C, Pickles A, Bailey A. Autism screening questionnaire: Diagnostic validity. Br J Psychiatry. 1999;175:444-51.

80. Ehlers S, Gillberg C, Wing L. A screening questionnaire for Asperger syndrome and other high- functioning autism spectrum disorders in school age children. J Autism Dev Disord. 1999;29(2):129-41.

81. Brown C, Dunn W. Adult/Adolescent Sensory Profile: User's manual. San Antonio: Psychological Corporation; 2002.

82. Bießmann F, Rukat T, Schmidt P, Naidu P, Schelter S, Taptunov A, et al. DataWig: Missing value imputation for tables. J Mach Learn Res. 2019;20(175):1-6.

83. Dunn W. The Sensory Profile: User's manual. San Antonio: Psychological Corporation; 
1999.

84. Stoelting Co. Touch Test ${ }^{\mathrm{TM}}$ Sensory Evaluators: Semmes Weinstein Von Frey Aesthesiometers. 2001. Available from:

https://www.stoeltingco.com/media/wysiwyg/58011_Touch_Test_Evaluator.pdf

85. Oldfield RC. The assessment and analysis of handedness: The Edinburgh inventory. Neuropsychologia. 1971;9:97-113.

86. Ghent L. Developmental changes in tactual thresholds on dominant and nondominant sides. J Comp Physiol Psychol. 1961;54(6):670-3.

87. Stoelting Co. https://www.stoeltingco.com/jvp-domes.html. Accessed 30 Sep 2021.

88. Bleyenheuft Y, Cols C, Arnould C, Thonnard J. Age-related changes in tactile spatial resolution from 6 to 16 years old. Somatosens Mot Res. 2006;23(3-4):83-7.

89. Van Boven RW, Johnson KO. The limit of tactile spatial resolution in humans: Grating orientation discrimination at the lip, tongue, and finger. Neurology. 1994;44:2361-6.

90. Gondan M, Minakata K. A tutorial on testing the race model inequality. Attention, Perception, Psychophys. 2016;78(3):723-35.

91. Cliff N. Dominance statistics: Ordinal analyses to answer ordinal questions. Quant Methods Psychol. 1993;114(3):494-509.

92. Cox RM, Moore JN. Composite speech spectrum for hearing and gain prescriptions. J Speech, Lang Hear Res. 1988;31(1):102-7.

93. Maeder PP, Meuli RA, Adriani M, Bellmann A, Fornari E, Thiran J-P, et al. Distinct pathways involved in sound recognition and localization: a human fMRI study. Neuroimage. 2001;14(4):802-16.

94. Rauschecker JP, Tian B. Processing of band-passed noise in the lateral auditory belt 
cortex of the rhesus monkey. J Neurophysiol. 2004;91(6):2578-89.

95. Occelli V, Esposito G, Venuti P, Arduino GM, Zampini M. Attentional shifts between audition and vision in autism spectrum disorders. Res Autism Spectr Disord. 2013;7(4):517-25.

96. Saggar M, King BG, Zanesco AP, MacLean KA, Aichele SR, Jacobs TL, et al. Intensive training induces longitudinal changes in meditation state-related EEG oscillatory activity. Front Hum Neurosci. 2012;6:256.

97. Brunet D, Murray MM, Michel CM. Spatiotemporal analysis of multichannel EEG: CARTOOL. Comput Intell Neurosci. 2011;2011:813870.

98. Perrin F, Pernier J, Bertrand O, Giard M, Echallier J. Mapping of scalp potentials by surface spline interpolation. Electroencephalogr Clin Neurophysiol. 1987;66(1):75-81.

99. Lopez-Calderon J, Luck SJ. ERPLAB: An open-source toolbox for the analysis of eventrelated potentials. Front Hum Neurosci. 2014;8:213.

100. Luck SJ. An introduction to the event-related potential technique. 2nd ed. Cambridge, MA: MIT Press; 2014.

101. Bleyenheuft Y, Wilmotte P, Thonnard J-L. Relationship between tactile spatial resolution and digital dexterity during childhood. Somatosens Mot Res. 2010;27(1):9-14.

102. Peters RM, Goldreich D. Tactile spatial acuity in childhood: Effects of age and fingertip size. PLoS One. 2013;8(12):e84650.

103. Kern JK, Trivedi MH, Garver CR, Grannemann BD, Andrews AA, Savla JS, et al. The pattern of sensory processing abnormalities in autism. Autism. 2006;10(5):480-94.

104. Weiland RF, Polderman TJC, Hoekstra RA, Smit DJA, Begeer S. The Dutch Sensory Perception Quotient-Short in adults with and without autism. Autism. 2020; 
105. Mayer JL. The relationship between autistic traits and atypical sensory functioning in neurotypical and ASD adults: A spectrum approach. J Autism Dev Disord. 2017;47(2):316-27.

106. Elwin M, Ek L, Kjellin L, Schröder A. Too much or too little: Hyper- and hypo-reactivity in high-functioning autism spectrum conditions. J Intellect Dev Disabil. 2013;38(3):23241.

107. Haigh SM. Variable sensory perception in autism. Eur J Neurosci. 2018;47:602-9.

108. Gaetz W, Jurkiewicz MT, Kilaru S, Blaskey L, Schwartz ES, Roberts TPL. Neuromagnetic responses to tactile stimulation of the fingers: Evidence for reduced cortical inhibition for children with Autism Spectrum Disorder and children with epilepsy. NeuroImage Clin. 2017;16:624-33.

109. Wood ET, Cummings KK, Jung J, Patterson G, Okada N, Guo J, et al. Sensory overresponsivity is related to GABAergic inhibition in thalamocortical circuits. Transl Psychiatry. 2021;11:39.

110. Kolodny T, Schallmo M-P, Gerdts J, Edden RAE, Bernier RA, Murray SO. Concentrations of cortical GABA and glutamate in young adults with autism spectrum disorder. Autism Res. 2020;13(7):1111-29.

111. Roberts TPL, Lanza MR, Della J, Qasmieha S, Hines K, Blaskey L, et al. Maturational differences in thalamocortical white matter microstructure and auditory evoked response latencies in autism spectrum disorders. Brain Res. 2013;1537:79-85.

112. Roberts TPL, Bloy L, Ku M, Blaskey L, Jackel CR, Edgar JC, et al. A multimodal study of the contributions of conduction velocity to the auditory evoked neuromagnetic response: Anomalies in autism spectrum disorder. Autism Res. 2020;13(10):1730—45. 
113. Hoth S. Computer-aided hearing threshold determination from cortical auditory evoked potentials. Scand Audiol. 1993;22(3):165-77.

114. Lightfoot G. Summary of the N1-P2 cortical auditory evoked potential to estimate the auditory threshold in adults. Semin Hear. 2016;37(1):1-8.

115. Pollock VE, Schneider LS. P3 from auditory stimuli in healthy elderly subjects: Hearing threshold and tone stimulus frequency. Int J Psychophysiol. 1992;12(3):237-41.

116. Campbell J, Sharma A. Compensatory changes in cortical resource allocation in adults with hearing loss. Front Syst Neurosci. 2013;7:71.

117. Goossens T, Vercammen C, Wouters J, van Wieringen A. The association between hearing impairment and neural envelope encoding at different ages. Neurobiol Aging. 2019;74:202-12.

118. Fjell AM, Walhovd KB. Effects of auditory stimulus intensity and hearing threshold on the relationship among P300, age, and cognitive function. Clin Neurophysiol. 2003;114(5):799-807.

119. United States Census Bureau. Population estimates, July 1, 2019: Sacramento County, California; Sacramento city, California; California; Davis city, California [Internet]. 2019. Accessed 30 Sep 2021. Available from:

https://www.census.gov/quickfacts/fact/table/sacramentocountycalifornia,sacramentocityc alifornia,CA,daviscitycalifornia/PST045219 


\section{Figures}

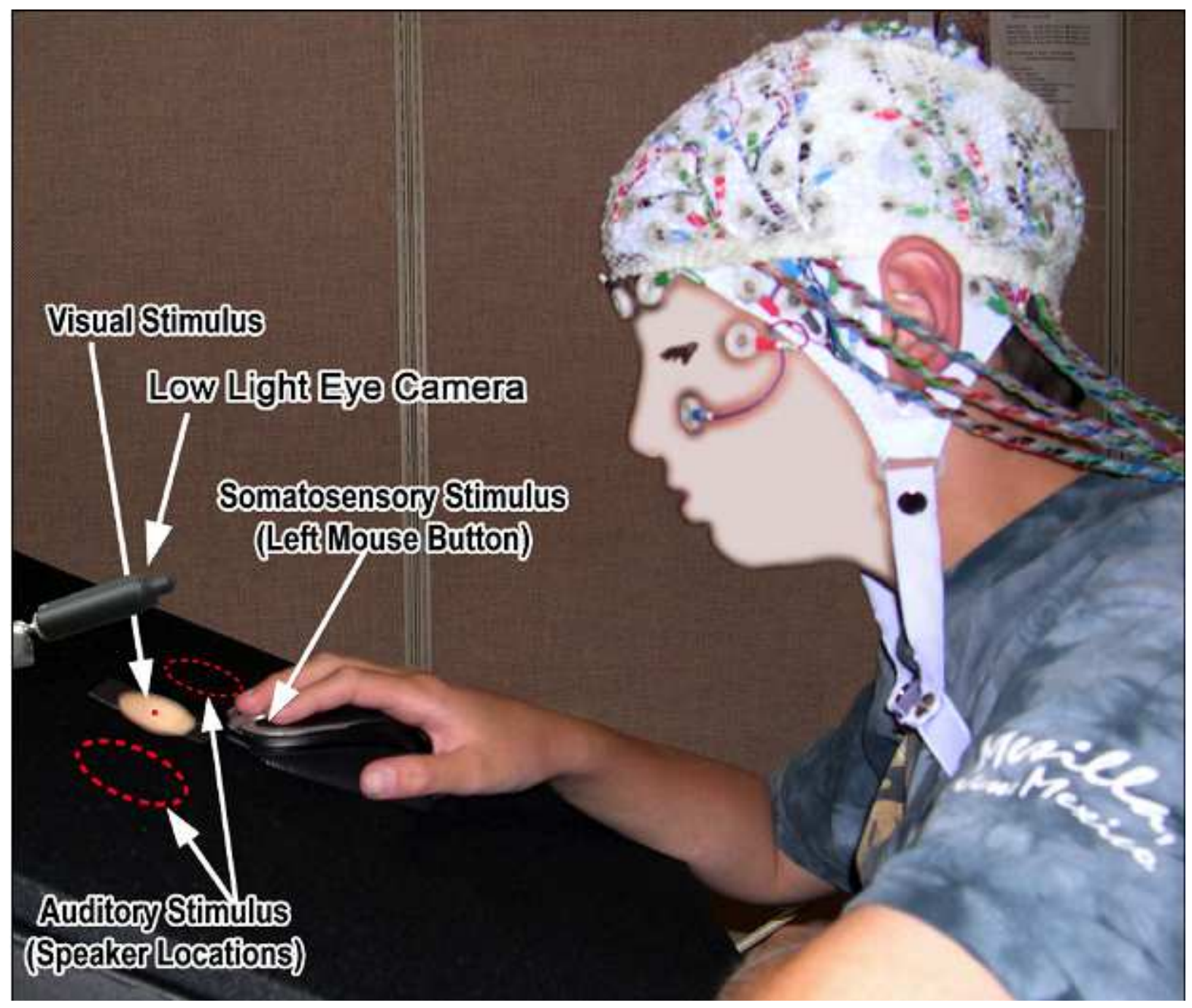

Figure 1

12-yr child pilot participant seated at the tri-sensory stimulation desktop. 

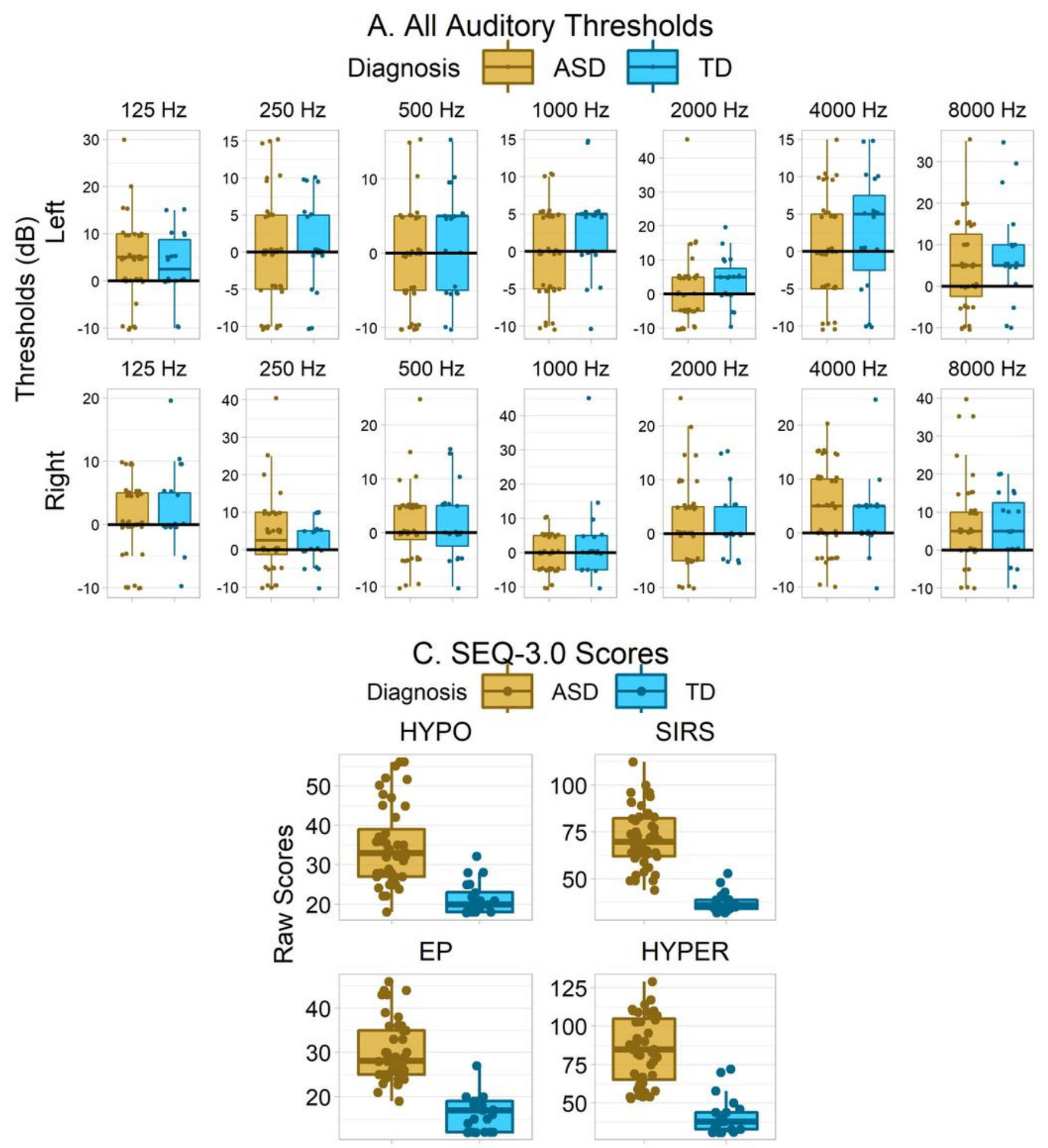

Figure 2

Raw Sensory Profile (SP) scores (panel A, top), Adolescent-Adult Sensory Profile (AASP) scores (panel B, bottom left), and Sensory Experiences Questionnaire-3.0 (SEQ-3.0) scores (panel C, bottom right) in the autistic and typically-developing groups. Groups significantly differed in all patterns except AASP Sensation Seeking (see Table 3). Lower scores on SP and higher scores on AASP and SEQ indicates greater levels of sensory patterns on each subscale. 

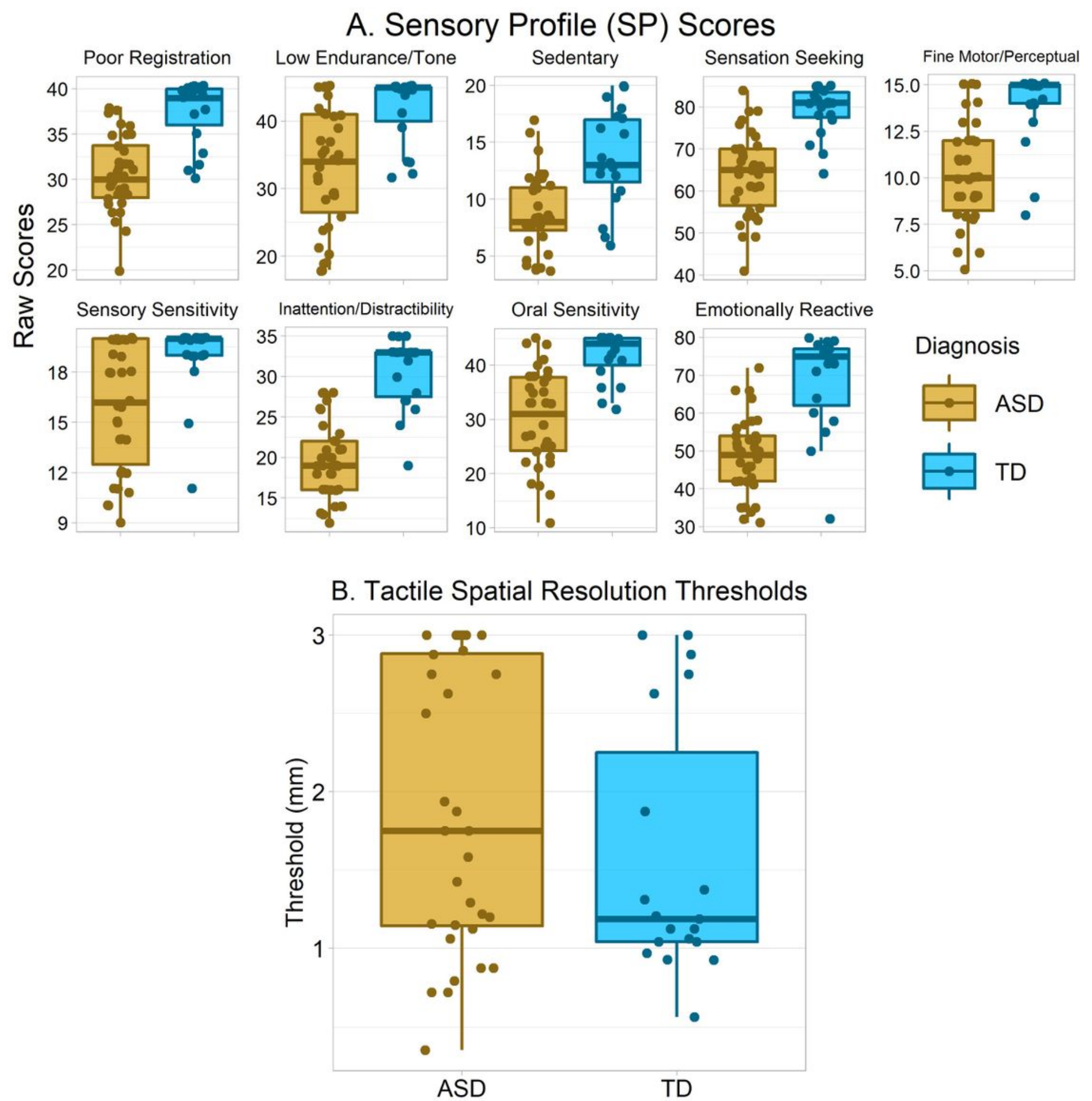

\section{Figure 3}

Hearing acuity in each group. No statistically reliable group differences were observed, despite the apparent trend towards greater auditory acuity in the ASD group in the left ear (panel B). Top panel, A: Hearing thresholds for each tone frequency and ear separately. Bottom panels, B-C: Pure tone average thresholds (collapsing across frequencies) for each ear. 


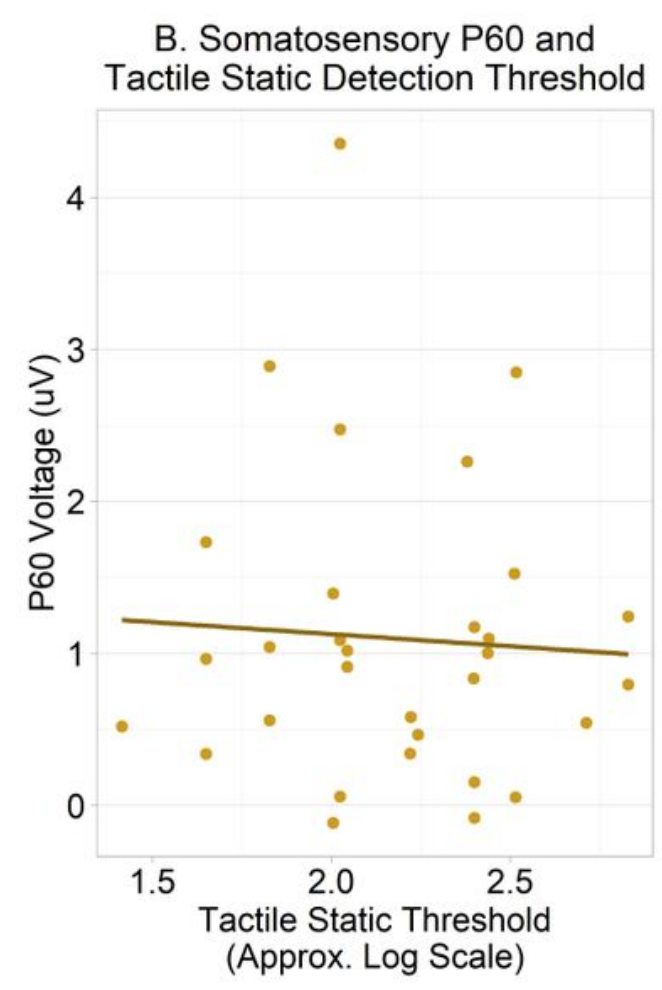

C. Somatosensory P60 and

Tactile Spatial Resolution Threshold

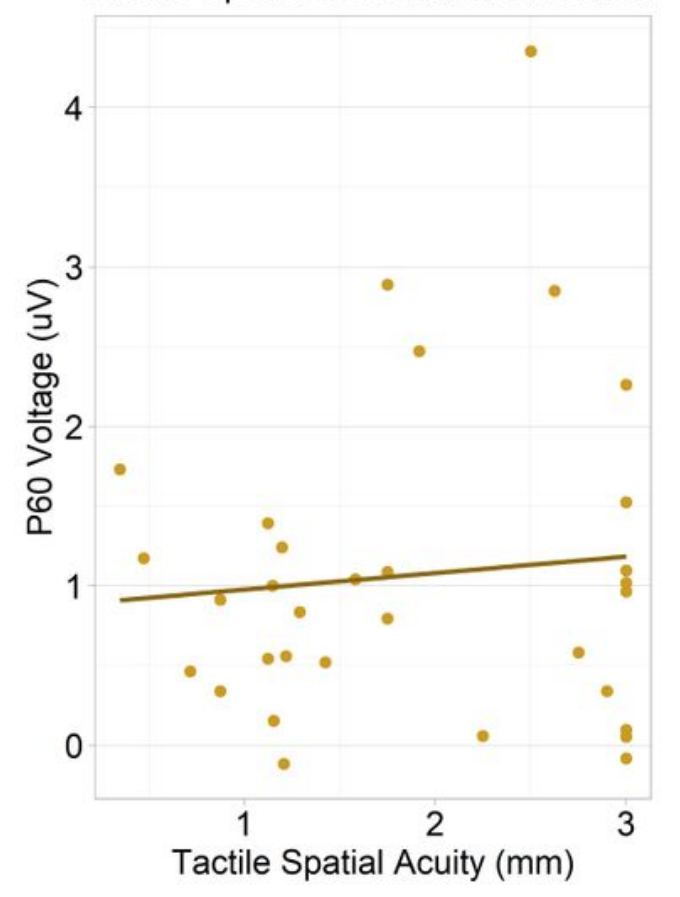

\section{Figure 4}

Tactile thresholds in each group. Left panel, A: Thresholds for detection of static (non-vibrating) tactile stimuli, specifically Von Frey hairs, using an approximate/theoretical log scale of forces provided by the manufacturer (Stoelting Co., 2001). Right panel, B: Thresholds for recognition of the orientations of tactile gratings of different widths (in $\mathrm{mm}$ ). 
B. Somatosensory P60 Waveforms

$$
- \text { ASD }- \text { TD }
$$

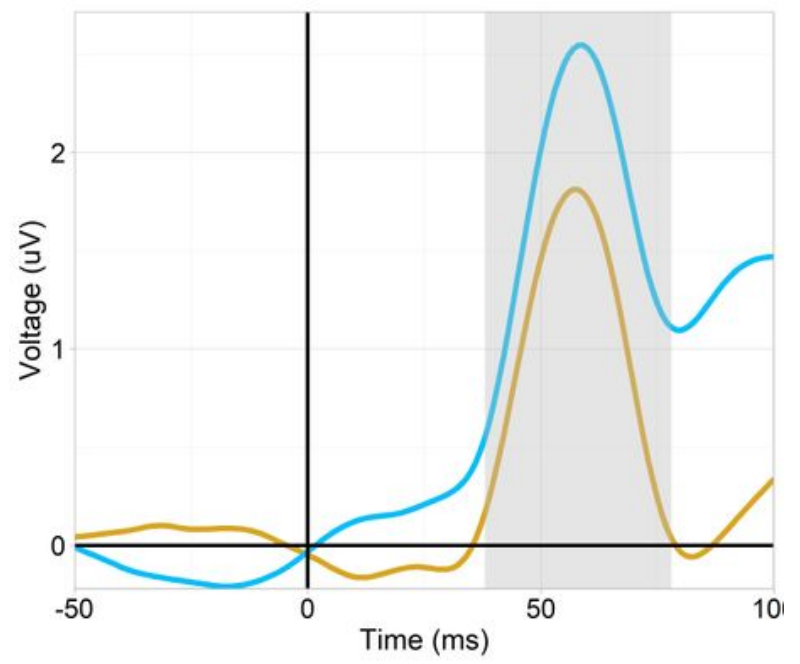

D. Somatosensory P60 Amplitudes
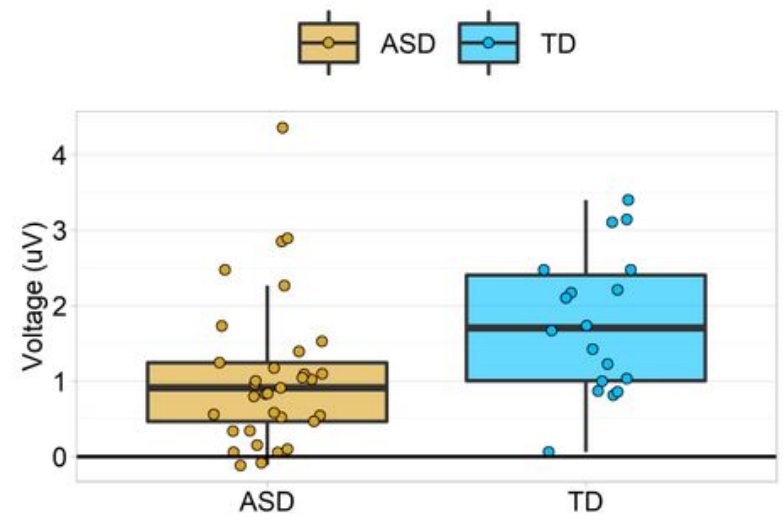

F. Somatosensory P60 Latencies

$$
\text { E ASD E }
$$

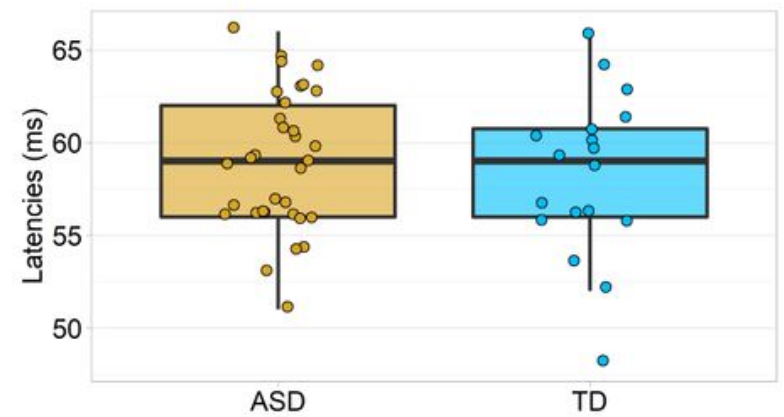

\section{Figure 5}

Plots depicting Auditory Tb and somatosensory P60 ERP responses. Top (panels A-B): Tb and P60 ERP waveforms in each group. P60 responses are contralateral (left hemisphere only), but the Tb is shown over each hemisphere. The gray highlighted regions represent the measurement windows (Tb: 135 - 195 ms, P60: 38 - 78 ms). Middle (panels C-D): Boxplots showing amplitudes of the Tb and P60 ERP responses. Amplitudes of both were greater in TD then ASD, but these effects dropped below the 
threshold for statistical significance after covarying for WISC PRI scores. Tb amplitudes were larger over the left hemisphere than the right. Bottom (panels E-F): Boxplots showing latencies of the Tb and P60 ERP responses. Latencies of the auditory Tb were faster in TD than ASD, but this effect was no longer significant after covarying for WISC PRI scores. Tb latencies were faster over the left hemisphere than the right.
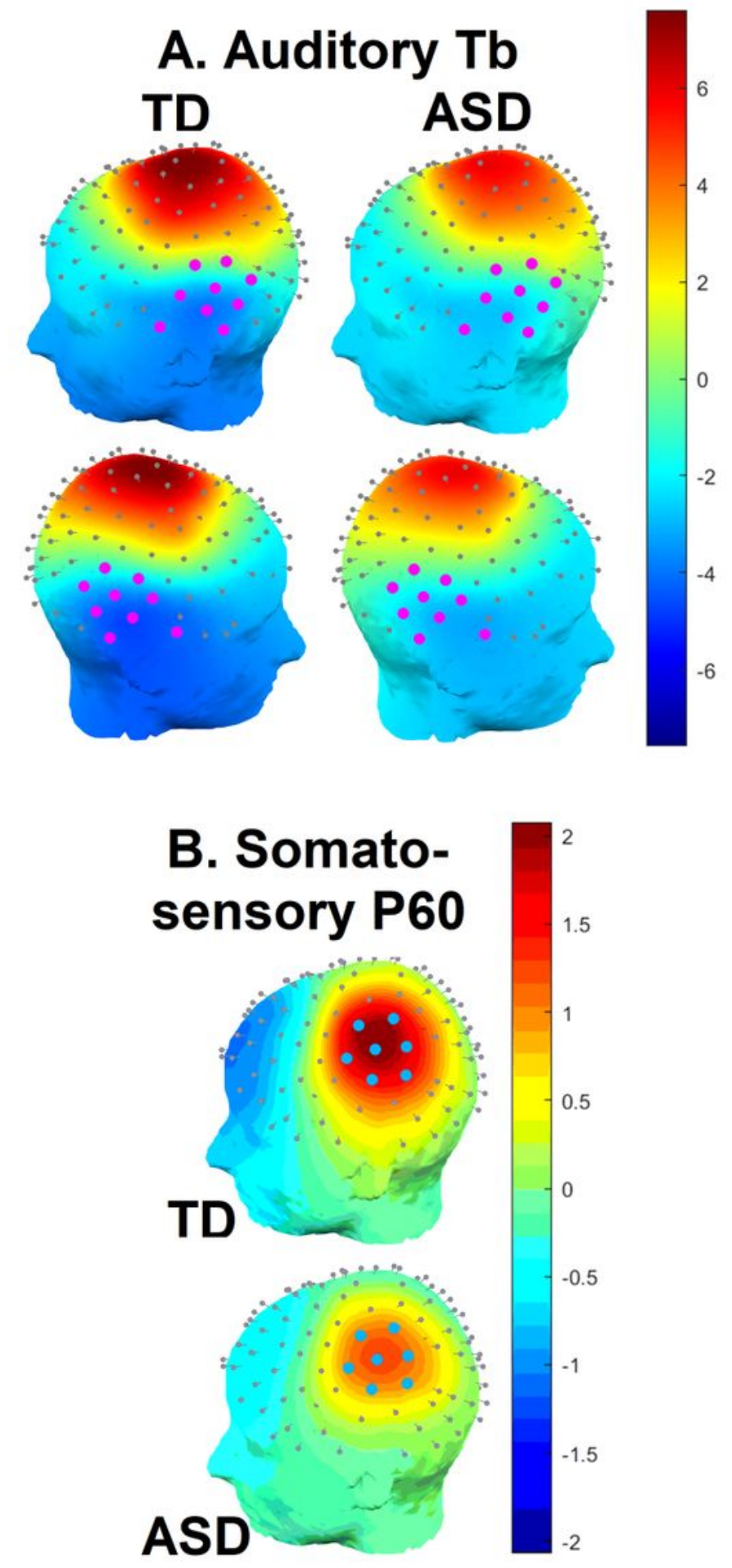

Figure 6 
Panel A, left: Splined scalp topographies over the left and right hemispheres in the time window of the auditory Tb response $(135-195 \mathrm{~ms})$. Electrodes used to the measure the Tb response are highlighted in magenta. Note that electrode positions are based on observations from a Polhemus digitizer and may appear slightly irregular as a result. Panel B, right: Splined scalp topographies over the left (contralateral) hemisphere in the time window of the somatosensory P60 response $(38-78 \mathrm{~ms})$. Electrodes used to the measure the $\mathrm{P} 60$ response are highlighted in blue.

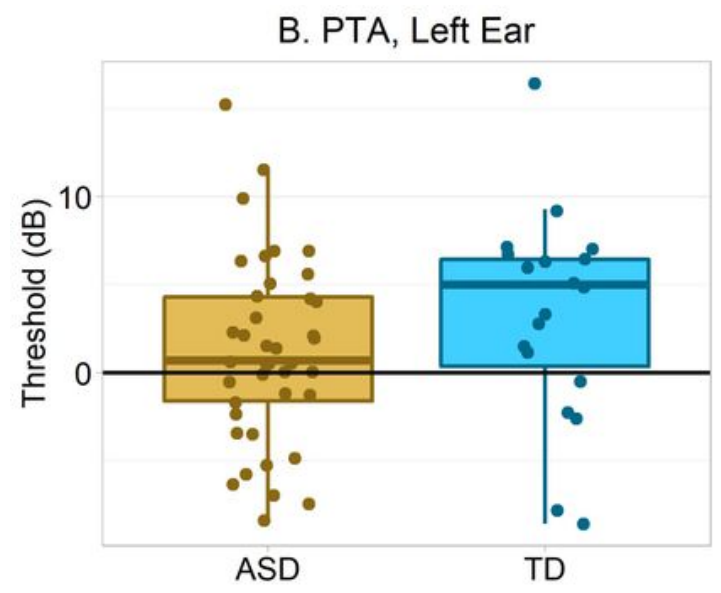

A. Tactile Static Detection Thresholds
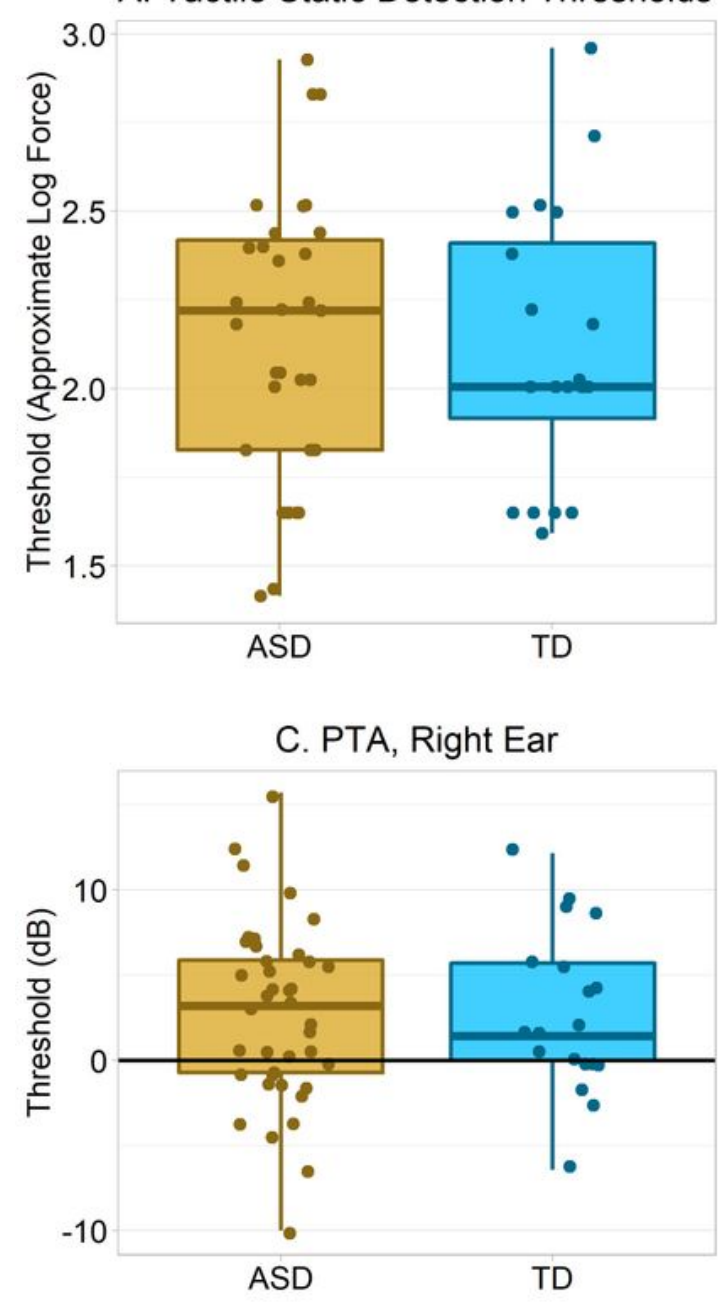

Figure 7 
Panel A, left: A negative correlation was observed between auditory Tb amplitudes (averaged across hemispheres) and pure tone average hearing thresholds (averaged across ears), corrected $p=.04$. Despite the apparent outliers, the corrected p-value remained significant when the association was measured ordinally (using Kendall's $\tau$ ). Panel B, centre: No association between contralateral somatosensory P60 amplitudes and tactile static detection (Von Frey hair) thresholds was observed. Panel C, right: No association between somatosensory P60 amplitudes and tactile spatial resolution (JVP dome) thresholds was observed.

\section{Supplementary Files}

This is a list of supplementary files associated with this preprint. Click to download.

- 20210930supplementaryfigure.docx 